Oliver Vogel (Berlin)

\title{
Berlioz als Harold - ein romantisches Selbstporträt im Zeichen des Liberalismus ${ }^{1}$
}

\author{
Non, les Bardes n'ont pu descendre \\ Dans ce fleuve des ans, qui roule l'avenir; \\ Si leur cythare en deuil se tait avec leur cendre, \\ Interrogeons ces lieux, pleins de leur souvenir. (V. Hugo)
}

Humoristisch trat Hector Berlioz seinem zukünftigen Publikum hinsichtlich der Uraufführung seiner neuen Symphonie Harold en Italie am 23. November 1834 mit der Frage entgegen: „Ich bitte Sie ernsthaft, mich darüber aufzuklären, was eine Symphonie namens Harold überhaupt bedeuten soll?" 2 Wenn auch scherzend, zog er doch die Aufmerksamkeit seiner Hörer auf den Titel. Es musste wohl mehr darin liegen als eine mit Dichter und Musiker gemeinsam anzutretende, bloß pittoreske Italienreise. Mit einer Symphonie nach Lord Byron, der schillernden, internationalen Symbolfigur der Romantik, konnte Berlioz anzeigen, welche Stellung er innerhalb dieser sich just erneuernden Bewegung einzunehmen trachtete. Längst waren ihre künstlerischen Belange auch von politischen Interessen vereinnahmt worden, die es mit zu bedenken galt.

Musikalische Selbstporträts zu erschaffen, war Berlioz von Anbeginn seiner Laufbahn natürlich erschienen. Sie halfen ihm in dem verzweifelten Bemühen, seine außerordentlichen Ansprüche gegen die Welt zu verteidigen. Fast immer liegt ein Bezug zu seiner eigenen Situation vor: Angefangen mit Beverley (1823/24), dem Spieler, der seine Pflichten gegenüber der Familie vernachlässigt, weil er sich einer risikoreichen Karriere verschrieben hat; dann der in Ungnade gefallene Ritter Kenneth aus dem Opernprojekt Richard en Palestine (1826), der, verkleidet als schwarzer Sklave, schließlich Anerkennung findet; des weiteren Lénor aus der Oper Les Franc-Juges (1826-29), dessen Schicksal als rechtmäßiger Thronerbe in derselben Weise von geheimen Gerichtshöfen bedroht scheint, wie die jungen Talente im nationalen Rompreiswettbewerb von der dunklen Rechtsprechung der wenigen Professoren, die die Musiksektion im staatlichen Akademieverbund (dem Institut de France) bildeten. Ebenso ist die frei erdachte Geschichte der Symphonie fantastique und ihrer Fortsetzung Le Retour à la vie, wie Berlioz bekennt, seine eigene. ${ }^{3}$ Die Methode der musikalischen Selbstdarstellung sagte ihm auch darüber hinaus zu und veranlasste ihn im Vorfeld von Harold en Italie zu dem berühmten Spruch: „Mein Leben ist ein Roman, der mich sehr interessiert. “4

1 Herzlich gedankt sei Hugh MacDonald, Peter Bloom und Arne Langer für ihre freundliche Unterstützung.

2 Berlioz, „Avis aux lecteurs assez désœuvrés pour lire mes feuilletons“, in: Le Rénovateur, 2. und 3. November 1834; in: Critique musicale d'Hector Berlioz (im Folgenden CM), hrsg. von H. Robert Cohen und Yves Gérard, Bd. 1, Paris 1996, S. 439.

3 Berlioz, Mémoires, XLIV/11: „le rôle de Lélio (c’est à dire le mien)“.

4 Brief an Humbert Ferrand vom 12. Juni 1833, Correspondance générale, hrsg. von Pierre Citron, Paris 1972-2003 (im Folgenden CG), Bd 2, S. 105. 
Um die programmatischen und musikalischen Selbstdarstellungsmöglichkeiten der Harold-Symphonie genau zu umreißen, ist auch jene Scène hérö̈que (Heroische Szene) zu befragen, auch bekannt als „Scène grecque“ oder „La Révolution grecque“. Berlioz zeigt sich hier bereits neun Jahre vor der Symphonie von einer Harold-Parodie Alphonse de Lamartines beeinflusst, die in der romantischen Bewegung heftige Diskussionen veranlasste. Spontan entworfen als Solidaritätsbekundung mit der griechischen Volkserhebung, die Byron selbst bis zuletzt persönlich unterstützt hatte, widmete Berlioz sein Werk einem nationalrepräsentativen Rahmen zu. Doch das angestrebte Prestige wurde ihm 1825 und auch in einem zweiten Anlauf 1833 verwehrt, obgleich er im durch Lamartine ausgelösten Streit um das Vermächtnis Byrons eine traditionalistische Position bezog. Er hatte somit Anlass zu zögern, seine zweite Symphonie nach Harold zu benennen, einer an sich wohl tadellosen Figur, die aber wegen ihrer stets im Raum stehenden Identifikation mit Byron selbst ein politisch aufgeladenes Sujet blieb. Die Szene ist somit als über musikalische Fragen hinausweisende persönliche Stellungnahme im Zeichen Byrons auch für die spätere Symphonie von Bedeutung und darf uns etwas umständlich beschäftigen, bevor wir unserem Hauptanliegen folgen.

Dieses zielt auf eine vertiefte, möglichst weit gehende Interpretation der Harold-Symphonie und ihrer inhaltlich bewusst unbestimmt gelassenen musikalischen Abläufe. Manches aus älteren, aufgegebenen Werken stammende musikalische Element bedurfte dabei einer neuen Sinnzuweisungen, oder Überarbeitung. Zwei Tendenzen sind zu differenzieren: Entgegen der zynischen Bedeutung des Symphoniefinales, wo die Gesetzlosen triumphieren, finden sich auch versöhnliche, die Brisanz des Themas kompensierende Impulse.

\section{Die „Heroische Szene“ im Kontext der französischen Byron-Rezeption}

Tatsächlich kehrte Berlioz, indem er sich 1834 zu Harold als dem Protagonisten seiner neuen Symphonie bekannte, zu einer Vorliebe zurück, die er lange schon gehegt hatte: Seit 1831 stand Byron auf einer Stufe mit seinen Lieblingsautoren. ${ }^{5}$ Was Harold angeht, hielt es Berlioz schon 1828 für bedeutsam, seinen Freunden die Ermunterung eines Musikkenners mitzuteilen, der zu ihm gesagt hatte: „Sie sind der Byron der Musik, Ihre Francs-JugesOuvertüre ist ein Childe Harold“ 6 Zweifellos reicht die Beschäftigung mit Byron, dessen Werke seit 1820 in französischer Übersetzung vorlagen, weiter noch zurück, als es die genannten Briefzeugnisse andeuten, allein durch die Natur der literarischen Orientierung, die Paris dem jungen Provinzler abverlangte. Sicher war Berlioz immer schon ein begieriger Leser gewesen, doch in seinen Urteilen keineswegs so unabhängig, wie es Briefe und Memoiren glauben machen. Offenbar übernahm er einige der Meinungen, die er im liberalen Blatt Le Globe vorfand. Indem er beispielsweise die Hauptperson aus James Fenimore Coopers Lederstrumpf als „einen Philosophen der Wüste“ bezeichnet, folgt er wörtlich der hier vorgebrachten Interpretation. ${ }^{7}$ Mit den Meinungen Schritt zu halten, die in den progressiven Zeitungen zum Ausdruck kamen, war für ihn als aufstrebenden Opernkomponisten unverzichtbar. Für die Suche nach einem unverbrauchten Sujet, das den Geschmack und

5 Brief an Nicolas Marmion am 15. September 1831, CG 1, S. 485.

6 Der Brief an Humbert Ferrand vom 28. Juni 1828, CG 1, S. 199, gibt Worte von Etienne-Jean-Baptiste Pastou wieder, einem privaten Musiklehrer, der 1835 Mitglied des Conservatoire wurde.

7 Brief an Nanci Berlioz vom 4. Juni 1827, CG 1, S. 155 und Le Globe V vom 24. Mai, S. 116. Dasselbe gilt für die irrige Annahme, dass der Protagonist ein einst zivilisierter Europäer gewesen sei. 
die Sorgen der Zeit traf, fanden sich hier wichtige Fingerzeige, zumal seit die Pressefreiheit unter Charles X. ein offeneres Wort zuließ.

Die Autoren, die Berlioz zunächst bevorzugte - Walter Scott, James F. Cooper und Constantin-François de Volney $^{8}$-, hatten im Gefolge von Chateaubriands amerikanischen Erzählungen René und Atala Rousseaus Zivilisationskritik und dessen Anpreisung ursprünglicher Tugenden erneuert. Die erzählerische Wiederaufnahme dieser bereits traditionellen Perspektive führte an Orte fern der urbanen Lebenserfahrung und erging sich in der Betrachtung historischer Stätten, Wüsten oder unberührter Orte. Childe Harold's Pilgrimage war in einem verwandten Geist der Neuorientierung geschrieben, der die sozialkritischen Themen in der Wahrnehmung hinter den politischen Aspekten zurücktreten ließ. Die durch Byrons frühen Tod im Jahr 1824 veranlasste Auseinandersetzung zeichnet sich durch eine entsprechende Tendenz aus. Als 1825 ein Meinungsstreit um die Deutung seines Schicksals entbrannte, war es keinem Pariser Künstler möglich, nicht mit Byrons Harold Bekanntschaft zu schließen. Eine Spannung zwischen der restaurativen Perspektive, die auf die Wiederherstellung nationaler Größe sah, und dem kosmopolitischen Liberalismus trat zutage.

Wie kam es dazu? Einer der berühmtesten Dichter Frankreichs, Alphonse de Lamartine, hatte es gewagt, einen fünften und letzten Canto zu den vier existierenden hinzuzudichten mit dem Titel Le dernier chant du pèlerinage de Childe Harold, wobei er das Heroische und den Tod Byrons, der durchweg mit Harold identifiziert wird, zum Vorwand seiner Reflektionen machte. Das rege Interesse des Pariser Publikums an dieser Hommage kann an der noch im selben Jahr erforderlichen Neuauflage des erst im Mai veröffentlichten Erstdrucks erahnt werden; ebenfalls noch 1825 begannen auch ausländische Raubdrucke zu kursieren. ${ }^{9}$ Lamartines Dichtung ragt aus der Flut der einzeln veröffentlichten Nachrufe in französischen Versen - Edmond Estève listet zwischen 1824 und 1825 ihrer vierundzwanzig auf ${ }^{10}$ - heraus, vor allem durch die kritischen Reaktionen, die sie entfachte. Seine scheinbar nostalgische Herangehensweise hatte unversehens den Finger in eine Wunde gelegt, die die Gesellschaft empfindlich betraf.

Gestorben war Byron an einem Fieber, während er persönlich den griechischen Volksaufstand gegen die osmanische Fremdherrschaft bei der Belagerung von Messolonghi unterstützt hatte; sein Tod veranlasste international Sympathiebekundungen. Die „griechische Revolution“, wie sie genannt wurde, hatte bedeutenden Einfluss auf das französische Selbstbewusstsein. Dichter, Maler und Musiker, darunter Namen wie Delavigne, Hugo, Delacroix und Rossini, vereinten ihre Kräfte, um ihre Landsleute zur Unterstützung für die Sache der Griechen aufzurufen. Stolze Erinnerungen an die Kaiserzeit wurden lebendig; der Revolutionsgedanke war wieder da. Doch Lamartine nahm das Beispiel der Griechen als Modell für die Rückkehr der Nation zu wahrer Größe nach dem Maß der Antike. Gegen diese restaurative Haltung, die sich die momentane Einheit der Nation missbräuchlich zunutze machte, wehrten sich die Liberalen vehement und griffen Lamartines Parodie wiederholt an: „Herr von Lamartines Geist bewegt sich in den Grenzen der Träumerei“, schimpfte die Zeitung Le Globe, „die freiheitlichen Ideen, die den Ruhm unseres Zeitalters

8 Berlioz' Vorliebe für Volney zeigt sich im Brief an seinen Vater vom 25. April 1825, CG 1, S. 91. Scott beschäftigte seine Fantasie seit 1826, die Lederstrumpf-Romane las er 1827.

9 Nachweisbar in Berlin (Staatsbibliothek) und Brüssel (Koninklijke Bibliotheek).

10 Edmond Estève, Byron et le romantisme français, Paris 1907, S. 533ff. 
ausmachen, sind ihm vollkommen fremd." 11 Wahr ist, dass es nicht die freidenkerischen Einstellungen Byrons waren, die Lamartine reizten. Seine zweite Méditation poétique von 1820 (Verse 59-62) hatte sich im Gegenteil an den noch lebenden Byron mit einer autoritären Forderung gewandt:
Mais cette loi [divin] dis-tu, révolte ta justice;
Elle n'est à tes yeux qu'un bizarre caprice,
Un piège où la raison trébuche à chaque pas.
Confessons-la, Byron, et ne la jugeons pas.
dies Gesetz Gottes, sagst du, empört dein Urteil und ist für dich nur ein komischer Einfall, ein ewiger Stolperstein für die Vernunft. Lass uns bekennnen, Byron, statt zu richten.

In tiefer Bewunderung für Byrons Thematisierung der unkontrollierten und leidenschaftlichen Kräfte des Geistes verstörte Lamartine die Unvereinbarkeit von dessen Blickwinkel mit einer religiösen Haltung. Der Globe dagegen, mit seiner politischen Agenda eines liberalen Blattes verteidigte Byrons Versuch, seine skeptische Haltung mit einem gewissenhaften und das Diesseits bejahenden Leben in Einklang zu bringen. So ging es bei der Anklage des Globe gegen Lamartine, Byron missverstanden zu haben, nicht allein darum, dass sein neues Werk die Zweifel Harolds aus religiöser Rücksicht unter den Tisch kehrte; schlimmer noch war die Tendenz, Byrons wirklichen Kampf gegen unterdrückerische Verhältnisse fortzuträumen und sein Tun mit den aristokratischen Idealen einer christlichen Empfindsamkeit, für die François-René de Chateaubriand und Germaine de Staël einstanden, zu ummanteln.

Der von Lamartines Byron-Imitation heraufbeschworene Konflikt zeugt von einer Uneinigkeit der romantischen Bewegung, in der sich die politische Unentschiedenheit der Restaurationszeit abbildet. Als gesellschaftliche Bewegung bleibt die Romantik überhaupt unverstanden, wenn man sie nicht auch als den Schauplatz eines fortwährenden Spiegelgefechts begreift, das zwischen Konstitutionalisten, gemäßigten Monarchisten, Ultraroyalisten, Bonapartisten, Republikanern und Liberalen ausgetragen wurde. Alle Künste waren davon betroffen, dass der liberale Geist der Unabhängigkeit und die von religiöser Empfindsamkeit geprägte autoritäre Abwehr im ästhetischen Anschauungsmodus der Romantik um eine mögliche Einheit rangen.

Als Gegenstück zu Lamartines Vereinnahmung der romantischen Symbolgestalt Byron, in der sich die Beständigkeit traditioneller Werte zeigte, lässt sich umgekehrt der Triumph Rossinis im Jahr 1823 als liberaler Aneignungsversuch anführen. Der Miroir vom 8. März 1823 zögerte nicht, den Italiener als denjenigen, „der das romantische Genre in die Musik eingeführt hat", zu begrüßen. Enthusiastisch wurde er von Presse und Publikum willkommen geheißen, denn die liberalen Züge seiner Musik wurden unmittelbar verstanden. Auch die Machthaber begrüßten in Rossini einen vielversprechenden Erneuerer des alten und politisch zwiespältigen imperialen Repertoires an ihrer national repräsentativen Opernbühne. Er war nicht weniger als eine Säule der nationalen Einheit.

Über das Musikleben hinaus, waren auch auf dem Feld der Literatur die abenteuerlichen Konzepte der Frühromantik - die Tugend des Vagen und der Wert subjektiver Erfahrung

11 Le Globe II, 6. August 1825, S. 731: „L'esprit de M. de Lamartine s'est arrêté dans la rêverie; il est parfaitement étranger aux idées de liberté qui font la gloire de notre âge." Eine Woche zuvor (30. Juli 1825, S. 718) hatte man ebd. lesen können: „M. de Lamartine n’a qu’une corde à sa lyre; il a traversé la vie en rêveur solitaire, il a peu vu, peu regardé; et quand il veut peindre la vie réelle, les idées comme les images lui manquent; il retombe dans sa continuelle adoration de l'infini, de la nature, des mystères de l'âme, rien de vivant ne s'échappe de son imagination: c'est toujours le même hymne (...) C'est toujours lui, toujours l'âme humaine accablée des mystères de la création." 
- in ein Stadium eingetreten, da die ihr innewohnende Mystik hinterfragt werden durfte. Das Geheimnisvolle, das lange eine unerlässliche Verteidigungsstrategie gewesen war, wurde nun, wo immer es sich in patriarchalischer und autoritärer Pose zeigte, sowohl ästhetisch als politisch mit Argwohn betrachtet. Der Grundstein zu Victor Hugos frühem Ruhm war von Anfang an dessen radikale Verweigerung jeder ästhetischen Bevormundung. Während Lamartine noch der christlichen Bilderwelt im Gefolge Chateaubriands verpflichtet blieb, hatte Hugo bereits die Notwendigkeit eines rationalen Konzeptes eingesehen, mit dem sich die Ideologie der Einbildungskraft kompensieren ließ. Sein Préface de Cromwell von 1827 wurde als Durchbruch gefeiert, da es sowohl die Doppelnatur des romantischen Erbes im "Grotesken“ und „Sublimen“ als auch deren mögliche Versöhnung thematisierte. Schon früher hatte er die Einheit der beiden von Chateaubriand und Byron verkörperten romantischen „Schulen“ betont. ${ }^{12}$ Mit einer neuen Doktrin von Harmonie und Ausgleich konnte er nun tatsächlich den Abgrund zwischen den politisch auseinanderdriftenden Parteien überbrücken, jedenfalls soweit es die Dichtung und das Theater anging.

Berlioz platzierte seine Heroische Szene dagegen ohne Vermittlungsambitionen in die hochangespannte Situation rund um Lamartines Byron-Dichtung. Als Schüler Lesueurs sympathisierte er mit dem akademischen Milieu des Conservatoire, das gegen die liberalen Tendenzen des öffentlichen Musiklebens an seinen republikanischen und imperialen Werten festhielt. Die sogenannte "Szene“, die sich in ihrer vierteiligen Anlage eher in den Dimensionen eines Opern-Einakters bewegt, war durch Berlioz' traditionalistische Haltung naturgemäß der geistigen Welt Lamartines verpflichtet. Das Libretto hatte sein Freund Humbert Ferrand beigesteuert, der sich auch in den Folgejahren als treuer Mitarbeiter an mehreren Opernprojekten verdient machen sollte. Berlioz begann diese Arbeit während der noch unentschiedenen Belagerung Messolonghis. In einem Brief an seine Schwester erwähnt Berlioz ausdrücklich die Wirkung allgemeiner Zeitfragen auf seine kompositorischen Aktivitäten: „Bin ich auf unbestimmte Weise von einer tiefen Bewunderung für irgendeine menschliche Konzeption durchdrungen, so brenne ich darauf, sie mitzuteilen, so laufe und fliege ich ..." ${ }^{13}$ Erfüllt von Lamartines Versen und befeuert vom Ausmaß der allgemeinen Bewunderung für Byron reagierte Berlioz mit einem eigenen Werk: „Nichts bewegt mich so tief und stürmisch“, sprach er zu sich, „wie der Anblick einer ruhmreichen Ehrenbezeugung gegenüber dem Genie oder gar dem Talent“. ${ }^{14}$ Der überwiegend martialische Charakter und auch bestimmte Metaphern wie „Sohn Spartas“ legen eine direkte Inspiration an Lamartines Versen nahe. Manche Wendungen machen sogar den Eindruck einer Imitation. Verse wie
Ils [les héros] s'avancent et la victoire
Die Helden rücken vor, und der Sieg
Rayonne sur leurs fronts poudreux
leuchtet auf ihren staubbedeckten Antlitzen;
La terre belle encor' de son antique gloire,
retentit sous leurs pas nombreux.
das von seinem antiken Ruhm weiterhin schöne Land
erzittert unter ihren zahlreichen Tritten.

nehmen auf Lamartines Aussicht, neu an antike Größe heranzureichen, Bezug. Die für den Dichter ausschlaggebenden Aspekte charakterisieren auch die Szene: Die Grandeur des Ereignisses nimmt im weiträumigen Schluss-Tableau Gestalt an, dem Christentum wird im dritten Satz durch ein Gebet der griechischen Frauen Tribut gezollt und die Rückkehr zur Antike erfüllt sich in der mystischen Heraufkunft des spartanischen Sängers Tyrtaios,

12 Victor Hugo, „Lord Byron“, in: La Muse française vom 15. Juni 1824.

13 Brief an Nanci Berlioz vom 12. Dezember 1825, CG 1, S. 100.

14 Ebd., S. 101. 
die sich inmitten des Finales ohne weitere Erklärungen allein durch entfernte Trompetenrufe ankündigt. Der Sänger bringt die Wende, indem er die Griechen zum Sieg inspiriert, doch nicht etwa, wie man erwarten könnte, indem er charismatisch seine Stimme erhebt, sondern indem er sie mit einem geräuschvollen Harfenschlag anfeuert, der sich als Begleitung zum unbeirrten Tritt angreifender Krieger schickt: „Quel bruit sur ces bords expire?“ fragen jene, die sein Herannahen zuerst gewärtigen. Um diesen Augenblick als Wendepunkt wirkungsvoll herauszustellen, wartet Berlioz hier überraschend mit der Sexte der bis hierher etablierten Dominante (G-Dur) auf. Sie ersetzt eine aufwändige Modulation und unterstreicht den mystischen Charakter des Musikers (Notenbeispiel 1), der durch seinen exaltierten Zustand die anderen unmittelbar mitzureißen versteht.

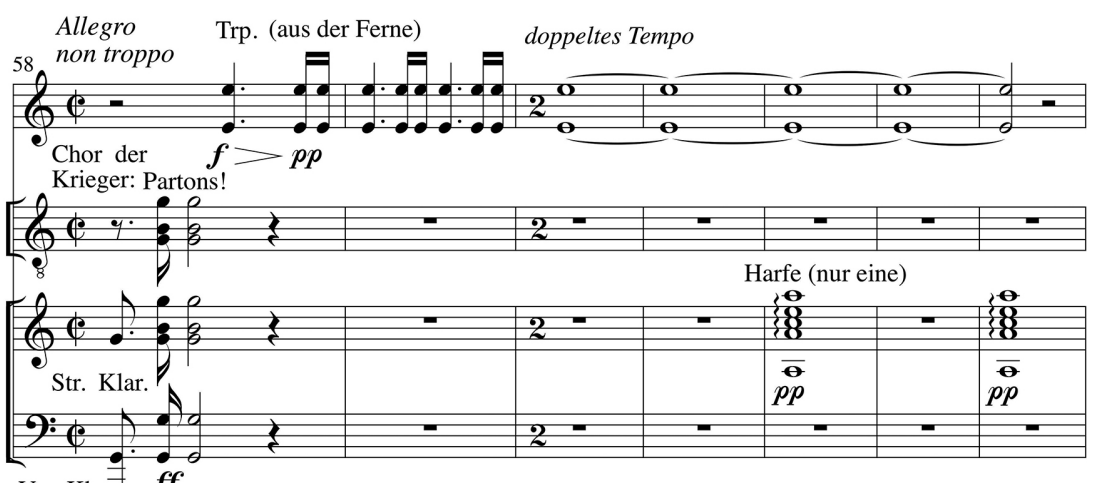

Vc. Kb.寻. ff

Notenbeispiel 1: Eintreffen des Tyrtaios im Finale der Heroischen Szene (Fassung von $1825)^{15}$

Um diesen Moment aus der Szene wirkungsvoll hervortreten zu lassen, dehnt Berlioz die vorangehenden und folgenden harmonischen Flächen weit aus, wobei er sie harmonisch stabil und statisch hält: Die sechzig Eröffnungstakte in C-Dur und die darauf folgenden hundert in a-Moll nehmen nahezu sechzig Prozent des gesamten Satzes ein. Er zielt hier auf eine Dramatisierung dieser weitgreifenden und homogenen Passagen durch einen einzigen katastrophischen Moment, während sein Lehrer Jean-François Lesueur derart langgestreckten und ungetrübten Harmonien eher die Funktion einer Hintergrundleinwand anwies.

Schätzte Berlioz wohl auch die Anziehungskraft des Sujets auf das Publikum richtig ein, unterschätzte er doch, wie heikel die „revolutionären“ Implikationen seiner Heroischen Sze$n e^{16}$ in der schwelenden Situation dem verantwortlichen Entscheidungsträger, dem Operndirektor Rodolphe Kreutzer, vorkommen mussten. Berlioz war so vorsichtig gewesen, den Titel von Scène hérö̈que zu Le Triomphe de la Croix umzuändern ${ }^{17}$ und sich der Unterstützung namhafter Künstler der Oper zu versichern. ${ }^{18}$ Dennoch lehnte Kreutzer es ab, die Szene im März 1826 im Concert spirituel zur Aufführung zu bringen. Er gab vor, dass sie zu viele Proben in Anspruch nehmen würde; doch anbetrachts der unkomplizierten Parti-

15 Nach New Berlioz Edition (im Folgenden NBE), Bd. 12a, hrsg. von Julian Rushton, Kassel 1991, S. $158 f$.

16 In den Memoiren nennt Berlioz die Szene La Révolution grecque; XI/3.

17 CG 8 (Supplément), S. 17.

18 Der Ballettmeister Pierre-Gabriel Gardel, die berühmte Sängerin Caroline Branchu, der Dirigent Henri-Justin-Joseph Valentino und der Verwaltungschef Dubois; siehe CG 1, S. 111. 
tur, muss man Berlioz wohl Recht geben, dass dies nur ein Vorwand war. ${ }^{19}$ Kreutzer sah wohl auch weniger auf die Musik als auf die heldenmütige Menschenmasse, die im Finale rachedurstig zur Freiheit marschiert, ohne auch nur einen Gedanken an die Möglichkeit dynastischer Ordnung zu verschwenden. Wie hätte er eine solche Provokation durchgehen lassen und ihr freimütig das königliche Privileg, ins Concert spirituel aufgenommen zu werden, zusprechen können?

Im Anschluss an den desaströsen Ausgang der Belagerung am 23. April 1826, mit dem sich die Anteilnahme an der griechischen Sache in der Bevölkerung noch verstärkte, konnten musikalische Umsetzungen dieses Sujets dem Publikum nicht länger vorenthalten werden. Diese ernteten den Erfolg, auf den Berlioz schon so viele Monate zuvor spekuliert hatte. Am Abend des 28. April erzeugte eine von Rossini geleitete Benefizveranstaltung für die Griechen im Publikum eine ganz besondere Atmosphäre nationaler Geschlossenheit, was von der Presse als ein seltenes und bedeutsames Ereignis gewürdigt wurde. ${ }^{20}$ Auch die Oper Le Siège de Corinthe, die im Oktober 1826 ihre Premiere erlebte, muss in diesem Zusammenhang genannt werden: Im Handumdrehen passte Rossini hierfür seine sechs Jahre zurückliegende neapolitanische Produktion Moametto II an den neuen Anlass an.

Eben diese freie Wandelbarkeit wurde von Traditionalisten wie Berlioz als Ärgernis empfunden. Um dem Erbe der französischen Oper gerecht zu werden, bedurfte es einer engen dramaturgischen Anpassung der Musik an die Szene und einer wahrhaftigen Malerei, so wie sie in der Tyrtaios-Szene gelungen war. Die Vorstellung einer leidenschaftlichen Angleichung war indes nicht, was gemeinhin für fortschrittlich galt: Rossinis Musik wurde mit Entzücken aufgenommen, weil ihre Musik die von Text und Szene vorgegebenen Bilder durch eigene Qualitäten in Wert zu setzen vermochte.

Berlioz interessierte sich brennend für die agitatorische Wirkung seiner Heroischen Szene und nahm sie in das Programm seines ersten privat veranstalteten Konzerts im Mai 1828 auf. Doch zu dem, was er sich von ihr versprochen hatte, nämlich eine Aufführung von nationalem Prestige, gehörte auch die staatliche Sanktion. Diesen ersehnten Auftrag bekam er schließlich anlässlich der Feierlichkeiten zum dritten Jahrestag der Julirevolution im Jahr 1833, wofür er die Chöre der Szene mit einer neuen wuchtigen Orchestrierung für Militärinstrumente und Kontrabässe dem besonderen Anlass anpasste: Zu feiern galt es die Rückkehr der Napoleonstatue auf ihren angestammten Platz auf der Säule des Vendôme-Platzes. Der Text war unter den veränderten politischen Bedingungen nicht länger zu beanstanden, denn er stellte ein erwünschtes Verbrüderungsethos der Massen heraus. Und doch blieb auch dieser Fassung, nachdem die Proben zumindest für den Schlusschor wunschgemäß verlaufen waren, die geplante Aufführung verwehrt. Der Grund dazu bleibt einigermaßen rätselhaft. Für die feierliche Aneignung des imperialen Vermächtnisses durch die liberale Monarchie waren nicht weniger als 600 Musiker, darunter 300 Sänger, in Bewegung versetzt worden. Dies sind die Zahlen, die Berlioz nennt und die mit denen des überlieferten Stimmenmaterials, ungefähr 245 Musiker und 300 Sänger, übereinstimmen. ${ }^{21}$ Adolphe Boschot dagegen teilt mit, dass 800 Musiker uneingerechnet des Chores angekündigt waren; ${ }^{22}$ vermutlich nahm aber nur ein Teil der für die Enthüllung vorgesehenen $\mathrm{Mu}$ siker auch an der musikalischen Zeremonie teil, für die eigens ein Amphitheater an den

19 Brief an Le Normant vom 15. Januar 1826, CG 1, S. 111.

20 Ludovic Vitet in: Le Globe III, 2. Mai 1826, S. 297 f.

21 Berlioz in einem Brief an Louis Penet am 15. Juli 1833, CG 8, S. 86 und Catalogue of the Works of Hector Berlioz, hrsg. von D. Kern Holoman, Kassel 1987, S. 33.

22 Adolphe Boschot, Hector Berlioz. Un romantique sous Louis-Philippe, Paris ${ }^{3} 1908$, S. 189 bzw. S. 191. 
Tuilerien errichtet wurde. Die 300 Trommler etwa, die den teilnehmenden Provinztruppen zugehörten, waren hierfür entbehrlich. Die gewaltigen Klangmassen ehrten das lang unterdrückte revolutionäre Erbe nur allzu gut: Zuletzt stellte sich die Realisierung als ein viel schwierigeres Unterfangen heraus als erwartet. Schon am Vortag waren diverse Zeitschriften und Broschüren konfisziert und eine Anzahl von Verdächtigen verhaftet worden. ${ }^{23}$ Als die Statue enthüllt wurde, störten Zwischenrufe die Zeremonie an der Place Vendôme, Krawalle waren zu befürchten. Angesichts der kraftvollen Wirkungen, auf die die Musik abzielte, wurde die Fortsetzung der Feier an den Tuilerien stark verkürzt und auf eine Ersatzveranstaltung im Opernhaus verschoben. In seinem tröstenden Brief an den Librettisten Humbert Ferrand behauptet Berlioz etwas fadenscheinig, dass die Szene nur entfallen musste, weil die Kerzen heruntergebrannt gewesen seien. ${ }^{24}$ Jedenfalls wurde die Veranstaltung mit der Heroischen Szene eines ihrer unwägbaren und aufrüttelnden Teile beraubt, während man auf die Musik aus Rossinis Guillaume Tell vertraute und sie bereitwillig erklingen ließ. Ob der Beitrag von Berlioz auch nur auf dem Programm jener Ersatzveranstaltung erschien, die für den 9. August, dem eigentlichen Jahrestag der neuen Monarchie, geplant war, ist zweifelhaft. Wie hätten dort der Massenchor und die gewaltige Anzahl von Blasinstrumenten, die für diese extravagante, auf die revolutionäre Vergangenheit verweisende Instrumentation benötigt wurden, erneut zur Verfügung gestellt werden können? Der imperiale Realismus und der experimentelle, ,geräuschvolle“Charakter mussten einer Académie Royale, von der man sich gediegenere Klänge versprach, für unwürdig befunden werden. Der Versuch zu einer revolutionären Repräsentation scheiterte an dem allzu gut gemeinten realistischen Anspruch.

Nach dem Desaster mit der heroischen Szene im Juli und der endgültigen Ablehnung seines oratorischen Großprojektes Le Dernier Jour du Monde im August musste Berlioz über seine weitere Karriere neu nachdenken. Das Rompreis-Stipendium lief aus; der einzuschlagende Weg war nicht sichtbar. Kam nach all den Anfeindungen, die er als Lélio provoziert hatte, nicht doch ein Ausgleich in Frage? Welche Rolle bei dieser Selbstfindung Harold en Italie spielen konnte, hängt mit Berlioz' Umgang mit Programmen überhaupt zusammen.

\section{Offene Programme und Selbstfindung}

Jacques Barzun vertrat als Erster die Meinung, dass die Programme, die Berlioz seiner Musik zudachte, austauschbar seien. Wenn auch die Allgemeinheit, mit der er diese These formuliert, einzuschränken ist, ${ }^{25}$ muss man ihm mit Blick auf die Symphonie fantastique und Harold en Italie vielleicht Recht geben, speziell für die Zeit vor ihren Premieren. In beiden Fällen wartete Berlioz so lange wie nur möglich, bevor er die endgültige Entscheidung über den Titel traf, und in beiden Fällen musste die Musik vollendet sein, bevor das Programm angekündigt wurde. ${ }^{26}$ Schon für die Symphonie fantastique hatte sich Verschie-

23 Ebd., S. 191.

24 Brief an Humbert Ferrand am 1. August 1833, CG 2, S. 110.

25 Sein Beispiel, die Fantaisie dramatique sur La Tempête, bezieht sich unlösbar auf die Charaktere und Szenen des Shakespeare-Dramas. Vgl. Lélio, NBE Bd. 7, S. 21 bzw. S. 239, wo der Protagonist selbst die Einzelheiten des Programms präsentiert.

26 Brief an Humbert Ferrand vom 16. April 1830, CG 1, S. 319. 
denartiges angeboten. ${ }^{27}$ Zunächst war sie als Faust-Symphonie gedacht gewesen. ${ }^{28}$ Doch da Goethe, dem Berlioz sein Opus 1, eine Bühnenmusik zu dessen Faust-Drama, übersandt und gewidmet hatte, ihn keiner Antwort würdigte, fehlte der Idee der Segen. Andere Wege standen offen, zu denen die einzelnen programmatischen Elemente die Richtung vorgaben. Die Ronde de Sabbat etwa nahm Bezug auf ein Gedicht aus Victor Hugos Balladen von 1826, das die katholische Liturgie in blasphemischer Weise parodierte; Hugo hatte damit seine Stimme gegen das Sakrileg-Gesetz erhoben, das im Folgejahr verabschiedet wurde. Ebenso provokativ war das über den Künstler verhängte Todesurteil, das auf eine Stelle in der von Alfred de Mussets 1828 veröffentlichten Fassung der Bekenntnisse eines Opiumessers von Thomas de Quincy zurückgeht.

Doch keines dieser Elemente des Finalsatzes hätte die Erzählstruktur der ganzen Symphonie zu tragen vermocht. Der Umstand, dass sich Berlioz schließlich zu dem radikal persönlichen Programm entschied, das wir heute kennen, war den emotionalen Wirren seiner Liaison mit der Pianistin Camille Moke im Frühjahr 1830 geschuldet. Diese Verbindung ermöglichte es Berlioz, auf seine damals noch unerwiderte Liebe zur irischen Schauspielerin Harriet Smithson als einer bloßen „Episode“ zurückzublicken und ein von Rachegefühlen durchzogenes Programm zu erstellen, das schockierend und zugleich als Liebesgeschichte anziehend wirken konnte. Der Titel selbst scheint einer Erzählung von Jean Vatout mit dem Titel L'Idée fixe entlehnt zu sein, die, wie der Globe zu Beginn des Jahres andeutet, „à ce qu'il paraît fait bruit dans le monde“. ${ }^{29}$ Vatouts Prosa klingt an das im 18. Jahrhundert beliebte Genre der sentimentalen Novelle an und beschreibt maliziös, wie sehr die imperiale Festkultur den allegorischen Traditionen des Ancien Régime verpflichtet blieb und als wie widerstandsfähig sich der Adel dabei erwies. ${ }^{30}$

Als Berlioz nun die ähnlich heterogenen musikalischen Stränge seiner zweiten Symphonie, Harold en Italie, zusammenband, konnte er auf die Erfahrung zurückgreifen, die er mit der Symphonie fantastique gemacht hatte, nämlich das Programm wie den Titel offen zu halten, um die Entstehung und Entwicklung musikalischer Einzelheiten nicht damit zu belasten. Berlioz baute, abweichend vom ursprünglichen Plan einer einsätzigen Phantasie, die Zahl der Sätze schrittweise aus, ${ }^{31}$ bis sie zu jener „neuen Symphonie von ganz anderer Art als die andere [die Symphonie fantastique]"32 angewachsen war: „Je comptais ne la faire qu'en deux parties mais il m'en est venu une troisième puis une quatrième." Doch noch immer zögerte Berlioz, sein Werk in die Welt zu setzen und zu taufen: „ma symphonie qui sera née et baptisée avant peu. "33 Dies geschah erst nach einem halben Jahr Arbeit, als die Partitur vollendet war. ${ }^{34}$

Größere Aufmerksamkeit als die Komposition nahm das „Retuschieren“ in Anspruch, bekennen die Memoiren. Die Materialien, die Berlioz unter der Hand hatte, entstammten zu einem guten Teil älteren Schichten, aus deren inhaltlichen Kontexten sie gelöst werden

27 Einen Überblick gibt Nicholas Temperley in Bd. 16 der NBE.

28 Brief an Humbert Ferrand vom 2. Februar 1829, CG 1, S. 232.

29 Le Globe (VIII), 25. Februar 1830, S. 42.

30 Jean Vatout, L'Idée fixe, 2 Bände, Paris 1830, Bd. 1 Kapitel XVII; auch eine Ballszene ist enthalten, welche die Intrige der maskierten Mönche der Cellini-Oper inspiriert haben mag: Bd. 2, S. 178-184.

31 Brief an Humbert Ferrand vom 19. März 1834, CG 2, S. 164.

32 Brief an die Schwester Adèle Berlioz vom 29. April 1834, CG 2, S. 176.

33 Brief an Joseph d'Ortigue vom 31. Mai 1834, CG 2, S. 185.

34 Ein erstes Anzeichen ist der Brief an Édouard Rocher vom 31. Juli 1834, CG 2, S. 188; das Autograph ist allerdings auf den 22. Juni 1834 datiert. 
mussten. Alte Bestimmungen wandelten sich, gingen verloren oder blieben erhalten, wurden herausgestellt oder verdunkelt. Während der Arbeit entwickelten sie sich nach seinem ausgeprägten Künstlerwillen zu einem Porträt seiner selbst und gerieten zum Medium einer unausgesetzten Selbstfindung. Was also konkret remodelliert wurde, war das in der Symphonie fantastique gegebene Bild des Künstlers, dessen Name sich in der Fortsetzung, Le Retour à la vie, als Lélio entpuppt hatte. Berlioz war reif, dessen Unbeugsamkeit zu überdenken und sich selbst als Lélio zu reformieren. Dessen aggressive Bühnenagitation widersprach dem klassisch-symphonischen Anspruch der Société des Concerts, die sich zu einer Neuauflage als „Lélio in Italien“ wohl kaum verstanden hätte. Berlioz’ Bühnencharakter musste aus dem Zustand fortwährender Rebellion herausgelöst werden und zu einem neuen, besonnenen Image, würdig eines Rompreisträgers, finden. Da Lélio bereits eine Art Childe Harold war, insofern er den Selbstreflektionen seines Autors in der Gestalt eines romantischen Helden Ausdruck verlieh, drängte sich die Harold-Chiffre geradezu auf. Als Chiffre steigerte sie sogar die schon von Byron bezweckte Verschleierung der Identität von Held und Autor, weil Harold ja bereits als Byrons Alter Ego verstanden wurde; Berlioz selbst war nun als bloß sekundäres Konnotat wohl versteckt. Feindseligkeiten, wie Berlioz sie sich als Lélio eingehandelt hatte, ${ }^{35}$ mussten an dieser perfektionierten Form des Byronismus, dem schützenden Mantel der notwendigen Selbstreform, abprallen.

\section{Schottische Todes-Phantasie und italienische Symphonie}

Ein unerwarteter Auftrag brachte diese Reform ins Rollen. Im Januar 1834 bestellte der gefeierte Virtuose Niccolò Paganini bei Berlioz ein Werk im Stil der Symphonie fantastique, mit dem er seine neue Stradivarius-Viola würdig in Szene setzen konnte. Ohne großen Verzug wurde es als „Les derniers instants de Marie Stuart, fantaisie dramatique pour orchestre, chœurs et alto principal“36 öffentlich angekündigt. Die Themen von Isolation und Exil, die bei seiner späteren Metamorphose zu Harold bestehen blieben, waren damit schon vorgegeben. ${ }^{37}$ In der verheißenen Thronfolge und dem Verhängnis der Königin spiegelte sich auch das von Berlioz immer wieder thematisierte Thema seiner gefährdeten Künstlerkarriere. Die überstürzte Ankündigung zeigt, dass Paganini und er sich ihrer Sache sicher waren. Eine Vielzahl von Gründen sprach für diese Wahl.

Zunächst war der englische Titel in mancher Hinsicht wünschenswert: Erstens hatte Paganini das Auftragswerk schon auf das Programm seiner für das nämliche Jahr geplanten Konzerttournee nach England gesetzt ${ }^{38}$ und wünschte sich ein speziell auf das dortige Publikum zugeschnittenes Thema. Zudem war dem Sujet durch seine historische Nähe zu Victor Hugos Theatererfolg Marie Tudor vom November 1833 in Paris bereits der Boden bereitet; auch Alexandre Dumas baute im Juni 1834 mit Catherine Howard darauf auf. Maria Stuart war dem Pariser Publikum zudem bereits ein Begriff durch die 1820 hier aufgeführte Schiller'sche Tragödie. ${ }^{39}$ In der Tat war Hugo Schillers innovativem Ansatz gefolgt: Frühere Generationen hatten sich des königlichen Themas allein in Hinblick auf

35 François-Joseph Fétis am 14. Dezember 1833 in Le Temps und am 15. in der Revue musicale.

36 Gazette musicale, 26. Januar 1834; vgl. auch CG 2 schon am 24. Januar 1834, S. 159.

37 Zur Bedeutung des Exils für spätere Werke siehe Jeffrey Langford, „The Byronic Berlioz: Harold in Italy and Beyond", in: Journal of Musicological Research XVI (1997), S. 209.

38 Brief an die Schwester Adèle Berlioz vom 20. März 1834, CG 2, S. 166.

39 Im März 1820 ging Schillers Drama als Marie Stuart in der Übersetzung von Pierre Lebrun in das Repertoire des Théâtre Français ein. Im August 1820 war es in einer von Michel Nicholas de Rougemont 
die Problematik einer weiblichen Regentschaft angenommen. Hugo aber setzte wie vor ihm Schiller einen Akzent auf die Verbindung von königlicher „Größe“ und weiblicher „Wahrheit“, wie auch sein seit der zweiten Auflage dem Stück vorangestelltes Vorwort unterstreicht. Drittens war das Drama um die Schottenkönigin geeignet, wertvolles Material aus der Intrata di Rob-Roy McGregor um einen schottischen Stoff Walter Scotts aufzunehmen. Die schottisch gefärbte Ouvertüre hatte bei ihrer Uraufführung im Frühjahr 1833 keinen überzeugenden Eindruck hinterlassen. All jene später in die Harold-Symphonie integrierten Passagen ragten bereits in der Intrata instrumentatorisch heraus, weswegen wir sie hier als Intermezzi bezeichnen. In einer dramatischen Szene um den Tod der Mary Stuart konnten sie frei von den Erwartungen, die sich mit dem Genre der Ouvertüre verbanden, wirkungsvoller zur Geltung gebracht werden:

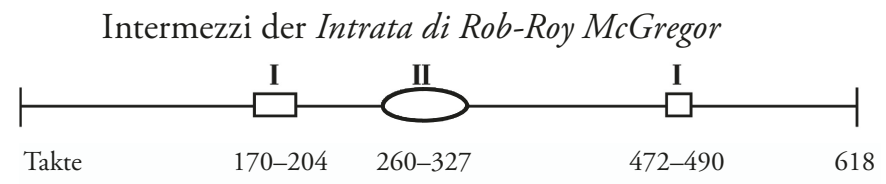

An ein solches symphonisches Drama knüpfte sich die Option einer zumindest stummen Bühnendarstellung. Berlioz dürfte davon geträumt haben, seiner Frau Harriett Smithson, die 1828 als Pantomimin in Paris Furore gemacht hatte, diese Rolle anzuvertrauen. Die Ankündigung als dramatisches Werk weist bereits auf den bald reifenden Plan einer Aufführung am Théâtre Nautique voraus. Die Musik hätte als Divertissement innerhalb einer vorwiegend vom Sprechtheater bestimmten Veranstaltung Platz gefunden. Das Haus plante, auch die Chöre einer gastierenden deutschen Operntruppe für seine musikalischen Divertissements im Mai und Juni 1834 hinzuzuziehen. ${ }^{40}$ Berlioz war bestrebt, eine Gelegenheit zu schaffen, bei der sich die Talente seiner Frau mit den seinen zugleich ins Spiel bringen ließen. Gemeinsam mit dem Dirigenten des Theaters, Narcisse Girard, plante er zu diesem Zweck eine „pièce géante“.41 Ein Auftritt von Harriet Smithson hätte im Rahmen der dramatisch motivierten und ihr persönlich zugedachten Musik, die von ihrem eigenen Ehemann geschrieben und von Paganinis Mitwirkung sanktioniert sein sollte, gewaltige Aufmerksamkeit erregen können. Die Schauspielerin und die Viola sollten sich dabei die Darstellung der Hauptperson teilen. Tatsächlich wurde Harriet, die nicht akzentfrei sprechen konnte, etwas später (im November und Dezember 1834) am selben Theater für eine musikbegleitete, stumme Szene engagiert. Es handelte sich um eine Theaterfassung von Hugos Le Dernier Jour d'un Condamné à mort, ${ }^{42}$ einer Darbietung, die zum folgenden Motiv in direkter Verbindung steht.

Schon im Programm der Symphonie fantastique kam die Thematik des Todesurteils prominent vor. Der Titel Les derniers instants de Marie Stuart versprach nun nicht länger bloß eine spannungsvolle Szenerie, er enthielt auch eine Anklage. Im Oktober 1833 war Berlioz eingeladen, einer Lesung von Hugos Marie Tudor beizuwohnen, einem „erneuten

und Etienne Merle den Konventionen des französischen Theaters angepassten, dreiaktigen Fassung am Théâtre de la Porte Saint-Martin gespielt worden.

40 Pierre Citron, Anm. zum Brief an Narcisse Girard vom 14. April 1834, CG 2, S. 174. Siehe auch $C M$ 1, S. 283f. und 459.

41 Brief an Narcisse Girard vom 14. April 1834, CG 2, S. 173.

42 Der Titel änderte sich zu La Dernière Heure d'un condamné à mort. Siehe CM 1, S. $459 \mathrm{ff}$. 
Plaidoyer gegen die Todesstrafe von Seiten des Mannes, der Le Dernier Jour d'un Condamné geschrieben hatte“. ${ }^{33}$ Letztere heiß umstrittene Novelle hatte bereits 1829 einen gewaltigen Eindruck auf Berlioz gemacht. ${ }^{44}$ Er zeigte Eifer, die gemeinsame Sache zu unterstützen, und Hugo seinerseits hatte ihn in die Arbeit an Marie Tudor mit einbezogen: Das Lied des leichtsinnigen Favoriten der Königin, des italienischen Edelmanns Fabiano Fabiani, desjenigen also, der auch zum Tode verurteilt wird, sollte Berlioz' Beitrag sein. Er lud Hugo auch im Dezember 1833 zu einer konzertanten Darbietung des Liedes ein, doch ob dieser es für sein bereits angelaufenes Stück übernahm, ist zweifelhaft. ${ }^{45}$

Enthält auch das Harold-Finale eine Todesszene? Der Tod der Maria Stuart war der alles motivierende Augenblick für das einsätzige Urkonzept der „dramatischen Fantasie“ und somit möglicherweise ein schon fertig konzipiertes Stück Musik. Das Programm zu Harold en Italie lässt Raum für diese Frage. Ob der Protagonist im Finalsatz stirbt, ist nie mit Gewissheit beantwortet worden. Liszt allein, als Eingeweihter, bekräftigt in seiner ausführlichen, von Berlioz abgesegneten ${ }^{46}$ Schrift zu Harold, dass der Schlusssatz das Ende des Helden bedeutet: „Ein zerschmetterndes Unisono [bei Takt 118] zeigt uns die fortbrausende Orgie, welche den Leichnam in rasendem Lauf durch blutigen Schlamm zieht“. Die von Liszt angedeutete schmutzige Gewalt bei der Schändung des Kadavers geht über das Bildrepertoire der Musik überhaupt hinaus. Sein Bericht scheint aber präzise hinsichtlich der Abbildung der Todeserfahrung ab Takt 80, indem er festhält: „Was auch die letzten Schläge dieses gebrochenen Herzens sagen möchten: Harolds Stimme kann nur noch verworrene, unverständliche Laute finden." ${ }^{\prime \prime}$

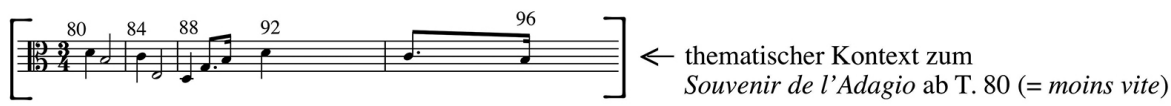

Soloviola
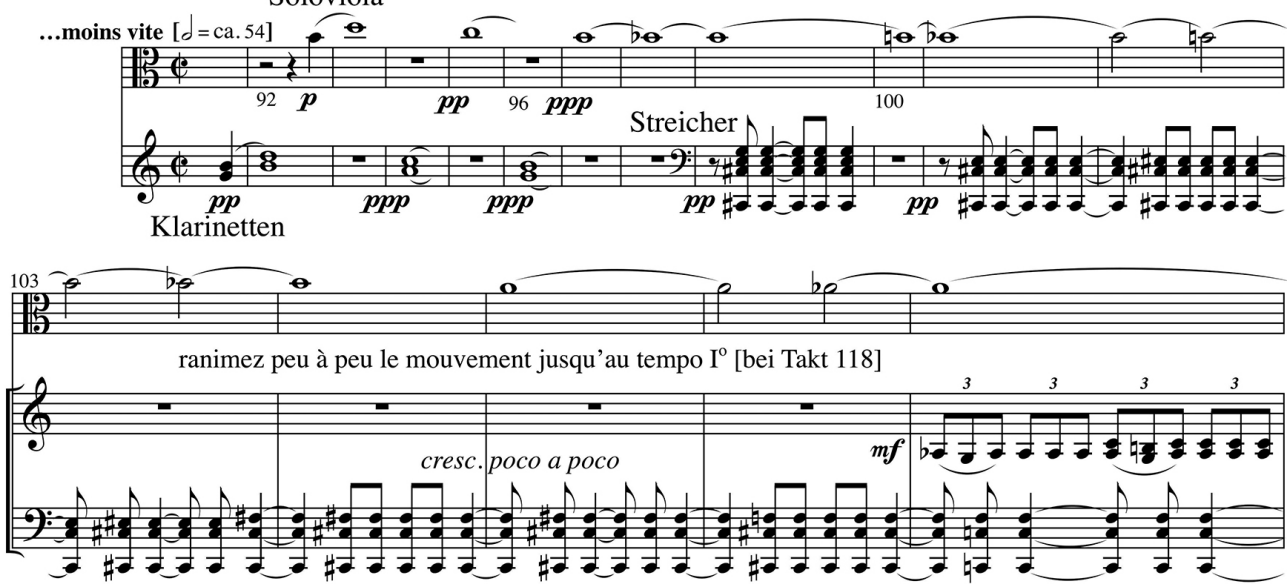

Notenbeispiel 2: Todesszene des vierten Satzes der Harold-Symphonie

43 Annie Ubersfeld, „Les manuscrits de théâtre de Hugo, Communication au Groupe Hugo du 17 Octobre 1998“, in: www.groupugo.univ-paris-diderot.fr/Groupugo/98-10-17ubersfeld.htm.

44 Brief an Nanci Berlioz vom 29. März 1829, CG 1, S. 244.

45 Siehe CG 2, S. 140 und Catalogue of the Works of Hector Berlioz, a. a. O., Nr. 66, S. 136. Das Lied ist verloren.

46 Brief an Liszt, CG 5, S. 149.

47 Franz Liszt, „Hector Berlioz und seine Haroldsymphonie (1855)“, in: Gesammelte Schriften, Bd. 4, hrsg. von Lina Ramann, Leipzig 1882, S. 93. 
Denn dass an dieser Stelle gestorben wird, erweist die Kennzeichnung der letzten Herzschläge ab Takt 99 (Notenbeispiel 2) mit jenem Todesrhythmus, den Berlioz in seinen früheren Werken oft als operative Idee ${ }^{48}$ eingesetzt hatte: im „Crucifixus“ seiner Messe von 1824 (ab Takt 38), in der Prière der Rompreiskantate Herminie von 1828 (ab Takt 29), in der Oper Les Francs-Juges (Akt I, Szene 1, ab Takt 152), im Todeskampf der Kleopatra zum Schluss der Rompreiskantate von 1829 und im ersten Satz der Symphonie fantastique (ab Takt 78). Von diesen fünf Beispielen stehen drei im Zusammenhang drohenden Todes und zwei repräsentieren ein tatsächliches Sterben. Aus dieser Sicht steht die fatale Bedeutung der im Beispiel wiedergegebenen Rhythmen außer Frage. Der Umstand, dass die kürzere Note je zwischen den Schlag fällt, macht aufgrund der kaum markierten, verschwommenen Metrik im Vorfeld keinen bedeutenden Unterschied zu den genannten Beispielen. Ist erst der primitive rhythmische Effekt etabliert, kommt es auch zu den charakteristischen starken Akzenten in der Mitte der Takte 102, 104 und 106.
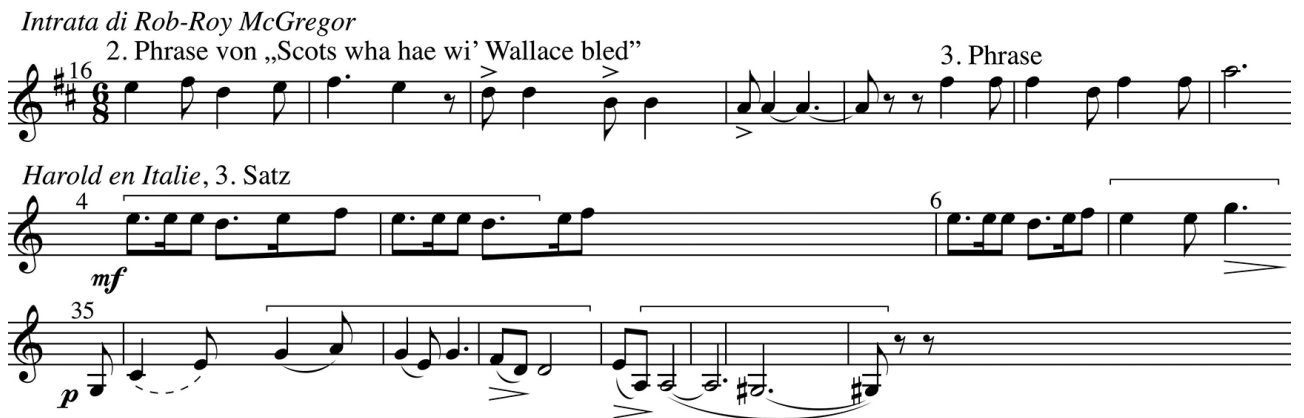

Notenbeispiel 3: Italianisierung des Intrata-Beginns für die Serenade in Harold en Italie

Byron hatte weder einen Heldentod für Childe Harold vorgesehen noch eine Orgie. Die mithin als mögliche Vorlage angesehene ausgelassene Feier der buntgemischten Truppen Ali Paschas aus dem zweiten Canto (LXXII) spielt nicht in Italien. Die Katastrophe und das zügellose Gebalge im Finale weisen auf Inhalte zurück, die mit Byrons Original unvereinbar blieben und im Programm nicht offengelegt werden konnten. Die Themen von Tod und Willkür hatten die Musik der dramatischen Phantasie um die schottische Königin mit einer Bestimmtheit belastet, die Berlioz nun hoffte, mit dem Attribut des Italienischen im Titel und einigem Lokalkolorit in der Musik zu punktuellen Nebenschauplätzen zu bagatellisieren. Eine Lösung der neuen Symphonie von den Geschicken der Maria Stuart konnte seit dem Schiffbruch der Pläne für das Théâtre Nautique frei erwogen werden. Vor allem dort, wo der schottische Charakter der Intrata oder der Stuart-Musik zutage trat, mussten zwangsläufig Anpassungen vorgenommen werden: Das Volkslied „Scots wha hae wi' Wallace bled“, welches die Intrata von Anfang bis Ende geprägt hatte, beschäftigte den Komponisten bei der Weiterentwicklung des Materials. Melodische Manipulationen brachten das schottische Drama auf den Weg zu einer italienischen Symphonie, wie die mit Klammern gekennzeichneten melodischen Entsprechungen in Notenbeispiel 3 zeigen. Die

48 Hans Heinrich Eggebrechts Begriff der „operativen Idee“ bezeichnet einen Querstand zum generischen System. Sie birgt einen festen Inhalt und beansprucht eigenständige Bedeutung, ob sie gleich in einer bloßen Begleitfigur besteht oder melodischen Sinn trägt. Vgl. Musik im Abendland, München 1991, S. 682 fff. 
vormals schottische Chiffre wandelt sich zu einer Serenadenmusik, mediterrane Lebensart symbolisierend und vorausweisend auf den späteren Titel Harold en Italie. Der Plan zu einer italienischen Symphonie stand übrigens längst im Raum: Von seiner Italienreise hatte Berlioz die „Idee zu einer Symphonie in zwei Sätzen“ mitgebracht, deren Titel Le Retour [de Napoléon] de la campagne d'Italie imperiale Nostalgie verheißt. ${ }^{49}$ Ein solches Projekt mochte ihn auch zu jener Reihe von Artikeln bestimmt haben, in der er seine aus Italien mitgebrachten musikalischen Eindrücke schilderte, beginnend mit der Beschreibung der Pifferari. ${ }^{50}$ Auf eine Symphonie, die ihre Charakteristik durch Melodik erwirkt, deuten auch die zahlreichen, nicht identifizierten Skizzenbucheinträge von 1834, die „größtenteils aus italienisierten melodischen Passagen bestehen " 51

Eine Bändigung der frenetischen Motive war Berlioz auch durch den Wandel seiner Lebensumstände auferlegt, die sich, verglichen mit den Entstehungsbedingungen seiner ersten Symphonie im Jahr 1830, stabilisiert hatten. Harriet Smithson war seine Frau geworden und mit Beginn des Jahres 1834 sichtbar schwanger; beide zogen an den noch ländlichen Montmartre in eine Wohnung, die sie in Anlehnung an Rousseaus Rückzug von der Welt als „Hermitage“ 52 bezeichneten. Berlioz war es gelungen, sich im Pariser Konzertleben bekannt zu machen. Seine Aussichten auf eine Karriere als Opernkomponist hatten sich verbessert. Er legte seine kategorische Verachtung für Rossinis Musik ab und analysierte dessen Guillaume Tell für die Gazette musicale ausführlich und mit Wohlwollen; ${ }^{53}$ auch für den Comte d'Ory, den er 1828 noch verächtlich gemacht hatte, fand er lobende Worte. ${ }^{54}$

Die Berlioz vertraute künstlerische Welt hatte sich zudem mit der Juli-Revolution prinzipiell verändert. Den neuen Erfordernissen ins Auge sehend verabschiedete er sich von den beiden Großprojekten, die er über lange Jahre verfolgt hatte. Weder Richter noch geheime Tribunale finden sich in den beiden Einaktern, die er aus seiner mehrfach revidierten Francs-Juges-Oper von 1826 zog: Der Cri de guerre de Brisgaw von 1833 sowie ein weiteres Projekt in vier Szenen ${ }^{55}$ bescheiden sich mit harmlosen und charakteristischen Tableaus. Ein anderer seit 1829 gehegter Traum war ein Weltgerichts-Szenario, dessen Keimzelle das Resurrexit der Messe von 1824 war. Nachdem ihm der Leiter der Oper unmissverständlich klar gemacht hatte, dass er es „nicht wage“, ein solches Werk aufzuführen, ${ }^{56}$ ließ Berlioz auch dieses skandalträchtige Projekt, das er in Italien noch zu einer dreiaktigen Oper ausgebaut hatte, ${ }^{57}$ fallen. Die darin enthaltene „wollüstige und orgiastische Szene, unterbrochen vom Schall himmlischer Trompeten und den Stimmen der die Toten zum Leben rufenden

49 Vgl. Skizzenbucheintragung nach Catalogue of the Works of Hector Berlioz, a. a. O., S. 129.

50 „Lettre d'un enthousiaste“, in: Revue européene vom 15. März 1832, CM 1, S. 79.

51 D. Kern Holoman, „The Berlioz Sketchbook Recovered“, in: Nineteenth Century Music VII (1984), S. 293: „unidentified material consists largely of italified melodic passages“.

52 Brief an Adèle Berlioz vom April 1834, CG 2, S. 176.

53 Die einschlägigen Artikel erschienen am 12., 19. und 26. Oktober sowie am 2. November 1834, CM 1, S. 401-434. Weiterhin verachtet Berlioz alle italienischen Opern Rossinis.

54 Brief an Nanci Berlioz vom 1. November 1828, CG 1, S. 212.

55 Zum Cri de guerre siehe Catalogue of the Works of Hector Berlioz, a. a. O., S. 41; der Vier-Szenen-Plan ist auf der Titelseite des Opernautographen skizziert, dessen Faksimile sich findet in: NBE, Bd. 4, Incomplete operas, hrsg. von Ric Graebner and Paul Banks, Kassel 2002, S. 329.

56 Brief an Ferrand vom 30. August 1833, CG 2, S. 113. Ein erstes Vorgespräch mit Louis-Désiré Véron hatte wohl (vgl. CG 2, S. 33) bereits Ende 1832 stattgefunden.

57 Le dernier jour du monde wurde im Juni 1833 als Oper (CG 2, S. 105), im Juli 1831 als ein „kolossales Oratorium" bezeichnet, $C G$ 1, S. 467; Briefe an H. Ferrand. Die Keimzelle war eine Vergrößerung des Resurrexit der Messe von 1824 zum Jugement Dernier (1829). 
Erzengel "58 findet vermutlich einen Widerhall im Finale der Harold-Symphonie, wo der Einsatz der Posaunen im Takt 215 die Orgie der Briganten in ähnlicher Weise mahnend unterbricht.

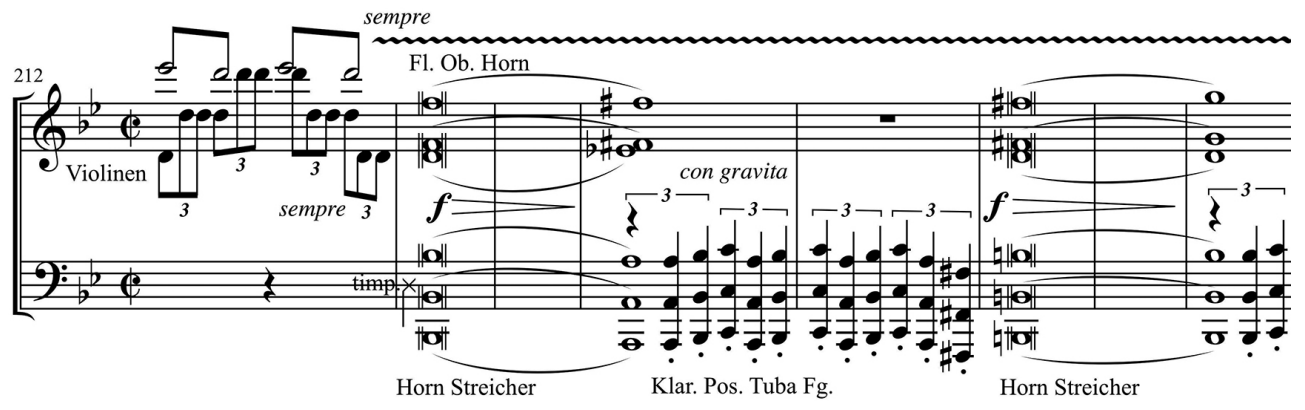

Notenbeispiel 4: Jenseits-Posaunen in der Orgie der Briganten

Es wäre übereilt zu folgern, dass es eine frisch erwachte politische Vorsicht war, die Berlioz veranlasste, seine aufbegehrenden Pläne aufzugeben. Zu überlegen ist, ob diese Großprojekte nicht in der Aufbruchsstimmung des siegreichen Liberalismus den Sinn, den sie unter der ungelösten gesellschaftlichen Spannung der Restauration haben konnten, eingebüßt hatten. Die Autorität von Gottes Gnaden, die im öffentlichen Musikleben auf die eine oder andere Weise, im Guten wie im Bösen, zum Gegenstand erhoben worden war, verschwamm und wurde für die altbewährten Allegorien und Parodien ungreifbar. Berlioz nahm die beobachtete Tilgung skandalöser Potentiale in Hinblick auf ein stabiles Einvernehmen mit den für ihn relevanten staatlichen Institutionen vor. Um insbesondere den Absichten der Société des Concerts gerecht zu werden, deren klassizistischem Verständnis von Symphonik dramatische Inhalte gattungsfremd erscheinen mussten, war von der Ankündigung einer schicksalhaften Geschichte abzusehen. Über den Tod des Helden wurde der Schleier des Italienischen gebreitet, hinter den nur enge Vertraute wie Liszt blicken durften.

\section{Schimmer des Verbrechens über dem Finale}

Neben vielen anderen versöhnlichen Gesten, auf die einzugehen sein wird, sublimiert auch das subtile Konzept von Innerlichkeit die Dramatik. Das Zusammenspiel von Autor und der in das Werk projizierten Künstlerfigur, dem byroneskem Alter Ego, ist feinsinniger als in der Symphonie fantastique. Die Logik der Harold-Symphonie beschreibt Berlioz mit den Worten: „Ich wollte die Viola, indem ich sie in die Mitte jener poetischen Erinnerungen versetzte, die ich von meinen Wanderungen durch die Abruzzen zurückbehalten hatte, zu einer Art melancholischem Träumer in der Weise des Childe Harold machen. "59 Die Ärgernisse, die, nach den Kapriolen des Lélio, eine weitere Selbstdramatisierung heraufbeschwören musste, konnten vermieden werden durch die Unterscheidung zwischen den Eindrücken des Autors und den Aktionen eines bekannten romantischen Charakters, der in dessen Erinnerungen eindringt. Dem Hörer wird dabei abverlangt, seine Aufmerksamkeit zwischen der vom Komponisten bereiteten Bühne und dem darin dargestellten subjektiven

58 Autographes Szenario zitiert nach Catalogue of the Works of Hector Berlioz, a. a. O., S. 128: „scène voluptueuse et orgiaque (...)".

59 Berlioz, Mémoires, XLV/16. 
Erleben einer durch die Violastimme symbolisierten dritten Person aufzuteilen. Sie lenkt von der Selbstdarstellung, welche Berlioz Anlass hatte, aus dem Blickfeld zu rücken, ab, ohne sie doch außer Kraft zu setzen. Unterschieden vom realen Raum der Erinnerung, ist die solistisch agierende Viola als bloßes Phantom der Einbildungskraft frei für einen bekenntnishaften Ausdruck der Subjektivität. Schon in der Retour à la vie war Berlioz auf der Fährte eines solchen Freiraums gewesen: Der Schattenchor (Nr. 2) ist als ein spontaner Schöpfungsakt inszeniert, welcher sich allein in der Vorstellung des realen Bühnendarstellers Lélio abspielt. Die Apologie des Imaginären spielt auch weiterhin eine Rolle, wie ein Zeugnis über Berlioz zu Beginn des Jahres 1833 zeigt: „Pour lui le drame est dans la pensée, dans l'âme,... et c'est un drame aussi passionné que ceux de Dumas. “60 Ebenso pocht Franz Liszt darauf, dass alles Tun und Handeln von diesem Fluchtpunkt der Imagination beherrscht ist: Die Idee mäandernder Leidenschaften sei „vielmehr auf die inneren Vorgänge gerichtet als auf die Handlungen gegenüber der Außenwelt“. 61

In diesem Gesamtkonzept der Symphonie stellt das Finale einen kritischen Wendepunkt dar. Mit dem Verschwinden der Viola hinter den triumphierenden Gesten der Briganten, stand eben dieses Einheit stiftende Zusammenspiel von individuellem Ausdruck und Erinnerungswelt auf dem Spiel. Berlioz beließ den ursprünglichen fatalen Sinn dieser Katastrophe zur Uraufführung im Dunkeln. Liszt hielt ihn daher auch weiterhin für gültig. Er wurde erst nachträglich revidiert, durch die kurze Epiphanie der Viola zwischen Takt 483 und 505, die den Charakter, wenn auch entstellt und unbedeutend, wieder verlebendigt. Das Manuskript zeigt, dass Berlioz, als er sich dazu entschloss, die Pilger an dieser Stelle wieder ins Spiel zu bringen, noch gar nicht an eine neuerliche Beteiligung der Person Harolds gedacht hatte. ${ }^{62}$ Es handelt sich um eine Ergänzung, welche, wie sich an Liszts Transkription ersehen lässt, vor $1837^{63}$ und möglicherweise erst angesichts von Erfahrungen nach der Uraufführung gemacht wurde. Ein allein den Räubern gehörendes Finale konnte empören, insofern die Umwendung Harolds vor Takt 118 auch als Hinwendung zu den Briganten missdeutet werden konnte.

Die apologetische Wiederbeteiligung der Viola, die Harold seine Beobachterrolle zurückgibt, war noch immer nicht die letzte inhaltliche Retusche. Mit ihr öffnete sich zwischen den beiden Enden des Finales eine Schicksalsdimension, die weiteren Erklärungsbedarf schuf. Diese Klärung lieferte Berlioz erst 1843, indem er eine Aufführung des Schlusssatzes während seiner ersten Deutschlandreise so kommentierte: „Alles sang und sprang und tobte in teuflischer Ordnung und Eintracht (...) während die Soloviola, der träumerische Harold, entsetzt fliehend, noch einige zitternde Töne seiner Abendhymne aus der Ferne hören ließ." ${ }^{34}$ Diese leichthin und wie nebenbei platzierte Deutung trug ein völlig neues Bild in das Programm hinein und löste eine seit der Uraufführung naheliegende Interpretation $\mathrm{ab}$, die Berlioz nicht länger genehm war: Dass Harold selbst zum Banditen werde, indem eine grausame Wirklichkeit die Schätze seiner Erinnerung beiseitefegt, ihn

60 Aus einem „V. F.“ signierten Artikel des Courrier de l'Europe, zitiert nach Boschot, Hector Berlioz, S. 150.

61 Franz Liszt, „Hector Berlioz und seine Haroldsymphonie (1855)“, S. 56.

$62 N B E$ 17, S. 217 verweist auf die Manuskriptseiten 253-256 mit 37 Takten (464-500): „two leaves replace an original version of unknown length, not involving the solo viola. Even after replacement, the addition of the alto solo in bars 483-505 was an afterthought."

63 Franz Liszt, Neue Ausgabe sämtlicher Werke, Suppl. 9, Budapest 2009, S. 157.

64 Voyage musicale en Allemagne et en Italie, Paris 1844 (in den Memoiren nach Kapitel LI), 6. Brief/11; zuerst erschienen im Journal des Débats am 23. September 1843. 
selbst aus der Beobachterrolle herauslöst und zum ohnmächtigen Mittäter macht. Berlioz wehrte sich mit der Rede von der Flucht seines Helden gegen die Aura des Verbrechens, die hartnäckig an ihm haftete. Auf seinen Reisen bestürzte ihn die Selbstverständlichkeit, mit der man ihn in solche Zusammenhänge stellte. Wissend, wie wenig diese Gerüchte auf ihn passten, entrüstete er sich, dass sie ihm in Wien „einfach so die Reputation eines wirklichen Briganten eingebracht hatten. Geschmeichelt fühlte ich mich nicht“, erzählt er, „das wäre zu viel gesagt, aber ob dieses exzentrischen Rufes, den der Himmel mir beschied, in der Tat geehrt. Ich sagte mir (...), dass ein leiser Schimmer von Verbrechen, seit Byron ihn in Mode gebracht hat, etwas allzu Distinguierendes ist, um, hat man erst das Glück, ihn zu besitzen, ihn nicht auch geflissentlich aufrechtzuerhalten; selbst wenn er ein durchaus unwürdiges Haupt bekränzt“. 65 Was Berlioz im Ausland erlebte, ging über den ihm willkommenen „Schimmer des Verbrechens“ offenbar hinaus.

Im Vorfeld der Uraufführung seiner Symphonie hatte Berlioz dieses Feuer noch bewusst geschürt. Als Lélio hatte er im Dezember 1832 von offener Bühne herab verkündet: „Gern würde ich ins Königreich Neapel oder nach Kalabrien gehen und mich dort irgendeinem Banditen verdingen, auch wenn ich so nur ein gewöhnlicher Räuber wäre... ich habe oft mit dem Gedanken gespielt. “66 Mit dem Lélio-Charakter hob Berlioz nach seiner Rückkehr aus Italien ein neues, entschlossenes Image aus der Taufe: Statt der Flucht in den Selbstmord, die den namenlosen Künstler der Symphonie fantastique umtrieb, strengt Lélio eine „Rückkehr ins Leben“ an. Er erscheint nicht länger isoliert, hat einen engen Vertrauten (Nr. 1) und wird von Orchestermusikern, die er seine Freunde nennt, bereitwillig unterstützt. Willensstark stellt er sich den Widernissen seines Berufes und zeigt sich bereit, gegen jene, die ihn herausfordern, anzugehen. Der Name Lélio war dem Theaterkenner aus den italienisch inspirierten Komödien Marivaux' bekannt, wo er (etwa in der Surprise de l'Amour) einen ähnlich unbändigen Charakter vorstellte. Das in Lélio erschaffene Selbstporträt steht mit der von Berlioz im vertraulichen Briefverkehr abgegebenen Selbsteinschätzung im Einklang: „Wie doch mein Leben schwankt. An einem Tag ruhig, dichterisch, träumerisch, an einem anderen wie ein streunender Hund, bissig und so bös wie tausend Teufel, das Leben verachtend und bereit, wegen einer Kleinigkeit allem ein Ende zu setzen. " 67 In den Beschreibungen seiner Erfahrungen als unabhängiger Reisender hielt Berlioz seine Sympathien für das Brigantenleben zurück, ${ }^{68}$ sorgte aber dafür, dass sie als Gerücht ihren Weg in die Öffentlichkeit fanden; Jules Janin berichtet: ${ }^{69}$ „Er lebte in den Bergen Italiens auf der Fährte der Briganten“, und Joseph d'Ortigue verrät: „Er durchstreifte das Gebirge bei Neapel mit geschultertem Gewehr; er lebte von der Jagd und suchte die Banditen in ihren Verstecken auf. ${ }^{70}$ Noch 1833 kokettierte Berlioz mit dem Banditenleben, als er einem Freund Schillers Räuber anempfahl, auf dass dieser ihm daraus ein Libretto in einem Akt anfertige. ${ }^{71}$ Ohne Zweifel sollte es das Bild eines unschuldig von der menschlichen Gesellschaft Verbannten zeichnen, der eine aggressive Natur an sich entdeckt.

65 Voyage en Autriche, en Russie et en Prusse (in den Memoiren nach Kapitel LIII), Brief 3/3, Wiener Episode von 1845. Zuerst erschienen im Journal des Débats am 19. Oktober 1847.

66 Übersetzt nach NBE, Bd. 7, hrsg. von Peter Bloom, S. 23.

67 An Humbert Ferrand am 12. Juni 1833, CG 1, S. 105.

68 Zuerst im März 1832, CM 1, S. 81; ausführlich im Juli 1834, ebd. S. 318 und S. 325-327.

69 Journal des Débats im Dezember 1832, nach Boschot, Hector Berlioz, S. 138.

70 Joseph d'Ortigue, Le Balcon de l'Opéra, April 1833, S. 316.

71 Brief an Thomas Gounet vom 24. Oktober 1833, CG 2, S. 126. 
Es ist somit nicht zu verwundern, dass das Briganten-Thema des Finales zum Thema der Viola in Verwandtschaft steht, insbesondere in der Gestalt, die es in der Serenade annimmt (Notenbeispiel 5). Dass dieses Lied des Verliebten im Harold-Thema präfiguriert ist, wird aus der Inversion der Takte 35 und 37 f. ersichtlich.
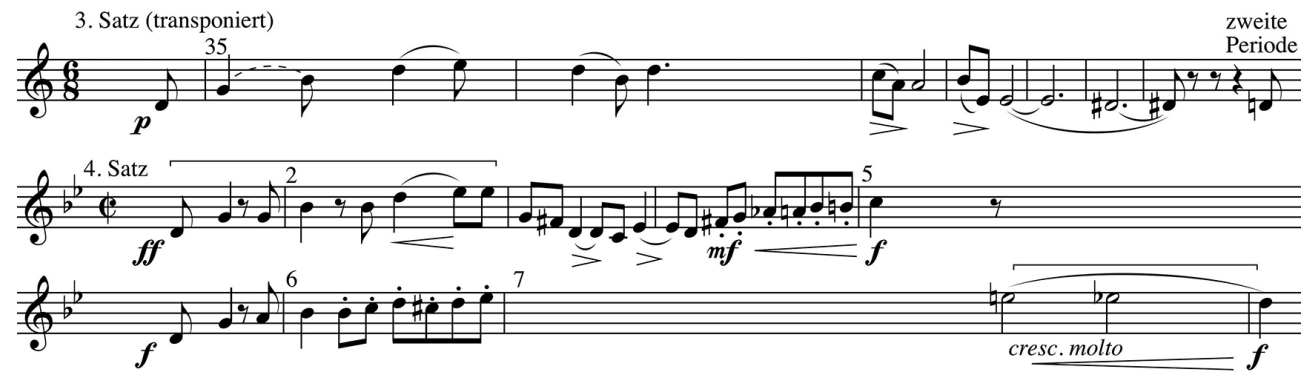

Notenbeispiel 5: Themenverwandtschaft im dritten und vierten Satz von Harold en Italie

Anders als die spärlichen Programmhinweise gibt die Musik eingehend Antwort darauf, in welcher Konstellation Harold zu den Briganten und Pilgern, den konträren Leitbildern seiner Tagträume, steht. Indem die Pilger einen ganzen Satz der Symphonie für sich beanspruchen, stehen sie im Rang eines grundsätzlichen Gegengewichtes zum Übermut der Räuber im Finale. Der zweite Satz ist keine bloß pittoreske Episode, die sich Harolds touristischer Neugier darbietet, sondern Kernstück einer übergeordneten inhaltlichen Konstruktion fern der italienischen Erinnerungswelt; in Berlioz' Reportagen kommen keine Pilger vor, und auch ihre erste Erwähnung durch den Komponisten ist nicht mit Italien verknüpft. ${ }^{72}$ Ihr Auftritt im Finale, der ohne die später beigemischte Viola noch größeren Ereignischarakter hatte, ist auch kein banaler Einspruch gegen jene Zügellosen, die ihrer Verdammnis - aller Mahnung durch jenseitige Signale trotzend (siehe Notenbeispiel 4 und erneut in den Takten 374 bis 394) - bewusst entgegensehen; Glaube und Hoffnung bleiben im Gegenteil mit dem Einzug der Pilger bei Takt 473 eine bloß schemenhafte, ferne Vision, die wie aus einer anderen Welt in die weithin etablierte Perspektive der Briganten vordringt gleich einer bald wieder erlöschenden Erinnerung.

Die Affinität von Harold und den Briganten, die wir zuerst betrachten wollen, wird in der Eröffnungspartie des Finales, den Reminiszenzen im Stile von Beethovens Neunter, differenziert dargelegt. Nicht alle Themen der Symphonie werden von den Briganten verworfen, indem sie wie Fuge und Serenade unvermittelt abgegrenzt bleiben; der Pilgerweise und den beiden abschließenden Soloreminiszenzen zollen die Räuber ihre Aufmerksamkeit. Im Angesicht der Pilger verharren sie über fünf Takte unschlüssig auf einer fremden Harmonie (29-34). Noch bevor die erste schwache Kadenz der Pilgerweise verklungen ist, mischen sie sich mit Gewalt ein: Sie unterbinden den Fortgang mit dem zweiten Teil ihres Themas (Takte 40-46), der mit zwei Motiven schließt, die durch den primitiven Oktavsturz und im anderen Fall durch einen willkürlich überlagerten Misston im chromatischen Gang (Notenbeispiel 6a) gewalttätig zu nennen sind. Wie ein Würgegriff hatte sich die nämliche Chromatik schon im ersten Satz an den Hochton des Allegrothemas im ersten Satz gelegt (Notenbeispiel 6b, T. 142: fis-f-e).

72 Brief an Humbert Ferrand vom 15. oder 16. Mai 1834, CG 2, S. 185. 


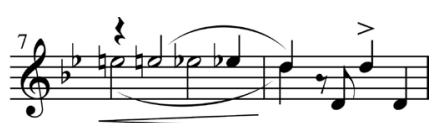

Notenbeispiel 6a: Gesten des Drosselns und Schlagens zum Beschluss des Brigantenthemas

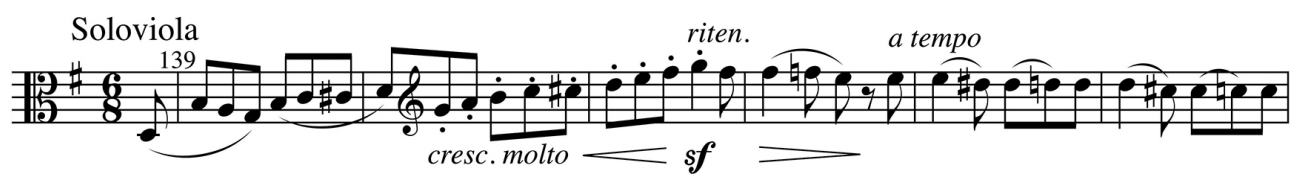

Notenbeispiel 6b: Allegrothema des ersten Satzes, zweite Periode

Das nämliche Allegro wird als erste von zwei Soloreminiszenzen ab T. 61 im Gegensatz zum Pilgerthema konstruktiv vorbereitet. Das Briganten-Thema schwingt sich ab T. $54 \mathrm{zu}$ einem hohen Halteton $\left(g^{\prime \prime}\right)$ auf und suggeriert so eine geweckte Erwartung. Eingeführt als

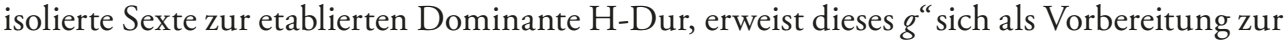
neuen Tonika C-Dur. Es ist die gleiche Pseudomodulation, die den Wendepunkt im Finale der Heroischen Szene brachte (siehe oben Notenbeispiel 1) mit einer vergleichbaren dramatischen Funktion: War es dort der mystische Tyrtaios, auf den sich der Blick hoffnungsvoll richtete, verengt sich der Fokus hier auf den Solisten Harold. Er bringt das Allegro indessen nicht zu Ende; inmitten der thematischen Entwicklung, eine Phrase zerteilend, übernimmt das Orchester die Führung, begradigt das triolische Maß zur binären Gangart der Briganten und beendet auch diesen Abschnitt mit den Gewaltmotiven. Die sich anbahnende Wandlung Harolds wird bekräftigt durch die folgende Adagio-Reminiszenz, vormals die Todesszene der Maria Stuart (Notenbeispiel 2). Sie prägt dem Vorgang den Stempel einer ultimativen Resignation auf. Der an seiner Mission verzweifelnde Außenseiter unterliegt den Versuchungen herrlicher Anarchie und gibt sich gemeinsam mit anderen einer wahnsinnigen Feier hin.

Als Brigant wird Harold von seinen Genossen ununterscheidbar und führt in der Gemeinschaft von Gesetzlosen eine verborgene Existenz. Und doch bleibt er in der Musik der Orgie präsent. Ab und an blitzt aus den Reihen des Orchesterkollektivs heraus die Rufterz-Initiale seines Adagio auf. Das signalartige, fallende Intervall pointiert als Motiv in den Takten 182 und 188 die Fortspinnung des wüsten Treibens. In den Takten 231-247 wird es wieder als Initiale verwendet, um darauf Harolds schmerzliche Alterationen der Takte 98-109 in Erinnerung zu rufen (Notenbeispiel 7). ${ }^{73}$

73 Die hier für die Takte 97-109 vorgeschlagene Phrasierung stimmt mit der „Klavierpartitur“ von Franz Liszt überein. Beide Versionen (vgl. Notenbeispiel 2) sind unkonventionell, und können nicht als Strichangaben missverstanden werden. 


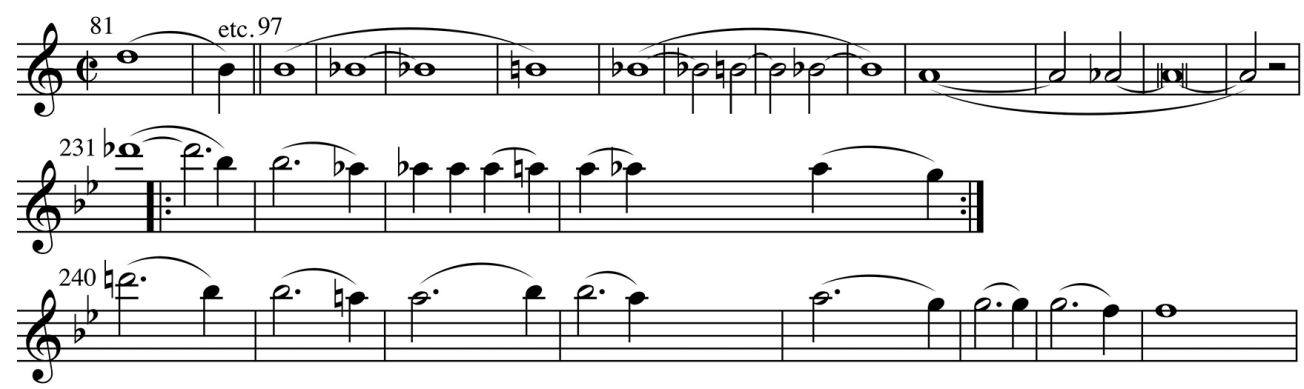

Notenbeispiel 7: Schicksalsalterationen des Finalsatzes und ihre Wiederkehr

Von hier an deutet sich auch die Wiederkehr des Gegenthemas der Pilger mit den Takten 254-256 und 267-269 bereits vage an. Es bedarf jedoch einer eingehenden Beschwörung, um es bei T. 464 vollends in die Erinnerung zurückzurufen. Im Vorfeld werden drei kraftvoll anrennende, verminderte Septakkorde (T. 459, 461 und 463) zunächst zweimal durch besagte Rufterz unvermittelt gestoppt; dann, auf den dritten Anlauf hin, öffnet sich der Abgrund eines tiefen, leeren und abrupt leisen Streicherklangs, der den Raum für die aus der Ferne herklingende Hymne aufspannt (Notenbeispiel 8a). Für die symbolische Bedeutung dieser Stelle stehen das von den drei Akkorden umrissene chromatische Total, die dreiteilige Gliederung und das Verschmähen regelgerechter Auflösungen ein.

Symbolisch für die Brigantenwillkür steht auch die Basslinie $c i s-c-h-b$, die den Epilog eröffnet und in der Folge strukturiert. Ein Bassgang $c i s-c-h$ hatte bereits Harolds ultimative Umwendung bei T. 99-110 markiert. Als Brigant blickt Harold hier auf die Standhaftigkeit im Glauben, die, wie der ferne Klang der Pilger versinnbildlicht, eine für ihn verlorene Tugend darstellt. In einer Art Zwiesprache der Orchestergruppen zeigt sich, dass die Mission der Pilger zwar fest gefasst, aber auch irritierbar ist. Treu im Ton bleibt ihre Hymne, die auf ihr Alpha und Omega verkürzt erscheint (I und II), gegenüber der chromatischen Willkür des Basses: Das unpassend suggerierte $b$ von T. 473 wird unverzüglich in das zum G-Dur der Hymne gehörige $h$ zurückgewendet. Ebensowenig vermögen die harmonischen Verwirrungen durch das erneute $c i s-c$ (T. 480-482) den Fortgang zu beirren. Doch das nun folgende $h-b$ bei T. 490 wirft den Pilgerton aus der Bahn; das $b$ lenkt ihn, als Leitton ais aufgefasst, nach h-Moll. Auf diesem Abweg fallen die Briganten mit der Durterz dis ein (T. 497), ein Dur, in das sich die Pilgerhymne nicht fügen will, wie die Wechselnote $c$ zu ihrem Schlusston zeigt (T. 499). Auch zerstört das Orchester das Metrum: Dreiergruppen von Halben (ab 499) und Vierteln (ab T. 502) sprengen den Alla-Breve-Takt. Tonarttypische Terzläufe von fis nach dis prallen mit fremdartigen von $h$ nach $g$ aufeinander, die nach G-Dur zurückverweisen. Die bei T. 505 neu entfesselte Musik der Räuber springt abrupt aus dieser Konfusion in die gewissermaßen angeeignete Pilgertonart G-Dur hinein. 

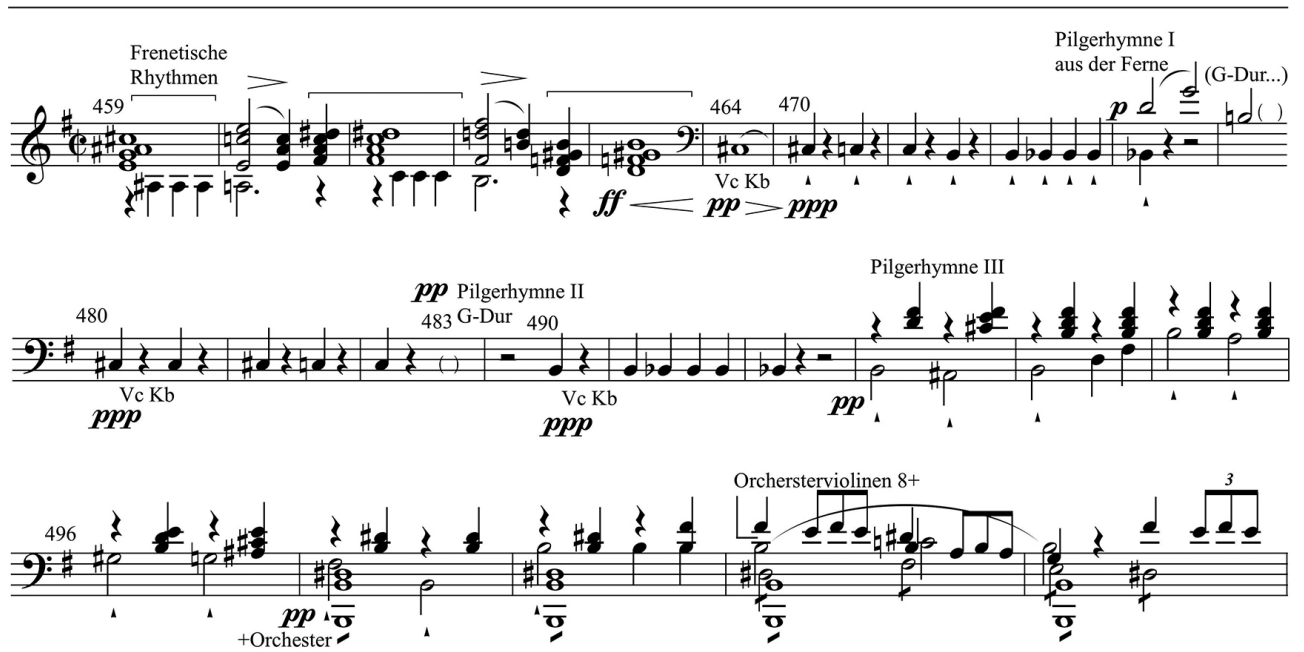

Notenbeispiel 8a: Finalsatz - Beschwörung und Epilog: erste Fassung ohne die Soloviola

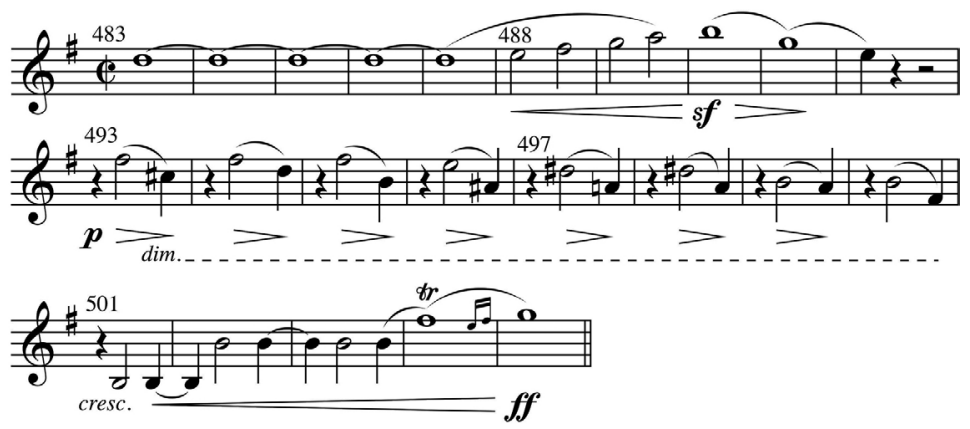

Notenbeispiel 8b: Finalsatz - die hinzugefügte finale Intervention der Soloviola

Auch ohne die Mitwirkung der Solobratsche ist also die finale Pilgerszene durch die Basslinie und das Schwanken zwischen $h$ und $b$ mit Harolds Schicksalsmoment (T. 97ff.) verknüpft. Die Viola als Verkörperung Harolds fügt sich bloß sekundär in das beschriebene Geschehen ein (Bsp. 8b). Sie imitiert das Gebaren der Pilger, ohne den Sinn des Epilogs zu erweitern: Ihr bei Takt 490 strahlend exponiertes Kardinal-Intervall $h-g$ passt zur Beharrlichkeit des G-Dur an dieser Stelle, und ihre Weglosigkeit ab Takt 493 sowie die Synkopen ab Takt 501 entsprechen der Bedrängnis, in die die Hymne gerät. Durch den beiläufigen Auftritt der Viola wird das ursprüngliche Konzept einer Konfrontation der Räuber mit ihrem Gegenthema, den Pilgern, bedenklich marginalisiert. Berlioz hatte, wie erläutert, diesen gewichtigen Grund: Es war geboten, den Verdacht auf ein Bekenntnis zur Kriminalität im Finale zu zerstreuen und den bloß beobachtenden Status des Protagonisten zu bekräftigen. $\mathrm{Zu}$ sehen ist aber auch, dass der Anlass genutzt wurde, um eine zusätzliche Facette des Solocharakters vorzuführen, die sich nicht in einer platten Opposition zum Brigantenleben erschöpft. Harold erscheint im Spannungsfeld der antagonistischen Parteien als Zerrbild seiner selbst und im scharfen Kontrast zu seiner früheren Existenz. Der Solocharakter erscheint im Milieu der Räuber gefährdet und unmöglich. Seine Selbständigkeit schwindet, wo sich der Glaube irritieren lässt. Die künstlerische Individualität, die das Spiel der Viola bislang ausgemacht hatte, entwickelt keine Qualitäten mehr. 
Die ersten drei Sätze hatten dem in den Memoiren formulierten Konzept der Parallelreaktionen auf eine italienische Szene gehorcht; sie betonten die Aspekte der subjektiven Erfahrung, ihrer Mitteilbarkeit und Originalität und folgten darin der älteren auf Rousseau zurückgehenden romantischen Tradition. Im Kontrast dazu steht das Finale im Zeichen wagemutigen Tatendrangs. Ein plötzlicher Umbruch findet hier statt, der auch für einen alternativen Betrachtungswinkel, der im Geistesleben Anerkennung und Berechtigung gefunden hatte, einstehen dürfte. Der vorwärtsdrängende Schwung der Briganten ist ein Bild für jene jüngere, liberal denkende Generation von Byron-Verehrern, denen die Idealisierung unbestimmter und vager Erfahrungen im Geiste Chateaubriands nicht länger zeitgemäß erschien. Seit 1825 stand, wie gezeigt, ihre Ablehnung der romantischen Byron-Aneignung durch Lamartine im Raum (vgl. Anm. 11). Die symphonische Anlage steuert insgesamt auf eine finale Konfrontation dieser konträren Weisen, Byron zu verstehen, zu. Es muss Berlioz gereizt haben, das ihm geläufige romantische Harold-Bild unter diesem anderen Blickwinkel durchzuspielen und die Möglichkeiten der Integration seines versonnenen Harold zu erproben. Das liberale Verlangen nach weltlicher Erfüllung kommt dabei mit einigem Zynismus als heilloses Brigantenleben zur Darstellung. Zynisch wirkt insbesondere, dass es in letzter Instanz siegreich und triumphal die Vorherrschaft behauptet. Harold, der bis hierher aus träumerischer Ferne das Geschehen beobachtet hatte, gerät in den Bann dieses auf Taten sinnenden, doch an sich unbestimmten Freiheitsdrangs. Seine Eigenart verblasst im Milieu des allgemeinen Aufruhrs. Bei seinem letzten Auftritt (Bsp. 8b) bleibt, was er zu sagen hat, bloßes Gestammel und antriebsloses Hadern; nur zu Recht wird es übertönt. Und doch regt sich in diesen schwachen Interjektionen ein letztes Mal so etwas wie ein Wille. Just in dem Moment, als das Orchester der Briganten in Takt 497 das Heft des Handelns mit einem Wechsel des Tongeschlechts nach H-Dur an sich reißt, setzt die Soloviola, indem sie vorsichtig auf leichtem Taktteil die dominantische Septime $a$ hineinspielt, ein Zeichen der Rückkehr zur Originaltonart der Pilger, dem E-Dur des zweiten Satzes, als einem der Kontemplation vorbehaltenen Raum; indes - die Regung verhallt ohne jedes Echo.

Unser Versuch Harolds Hinwendung zur Gesellschaft der Räuber im Finale als Teil eines Selbstbildnisses zu verstehen, kann in Hinblick auf Berlioz' Leben konkret bestimmt werden. Seit dem Dezember 1833 hatte er seinen Platz im offiziellen Musikleben eingenommen, als er einwilligte, wöchentliche Feuilletons abzuliefern. Bis dahin war er ein nur gelegentlich im Licht der Öffentlichkeit erscheinender Außenseiter geblieben. Als Kolumnist war er nun selbst Teil eines Gerichtshofes der Künste, wo Hinrichtungen und Willkür an der Tagesordnung waren. In derselben Weise wie die Brigantenmusik die natürliche Vorreiterfunktion des Soloinstruments in der Symphonie usurpiert, drängte dieser vom Daseinskampf aufgezwungene Schritt seine Komponistenkarriere an den Rand. Dabei endet Berlioz' Pilgerweg vorläufig wie der seines symphonischen Helden in Gefahren: begonnen in der friedfertigen Absicht herauszufinden, welches Schicksal ihm in dieser Welt beschieden ist, mündet er mit der Einwilligung in die Publizistenlaufbahn in eine berufsbedingte Bestimmtheit, die zwangsläufig empörte Reaktionen provozieren musste. Das von prägnanten Rhythmen bestimmte Zusammenleben der Räuber, das den „sentimentalen Plauderton“74 der Harold-Darstellung von diesem Punkt an ersetzt, bildet, im Unterschied zu den musikalischen Selbstdarstellungen der Vorjahre, den mit sich hadernden Künstler nicht länger als unentschieden $a b$. 
Als der gealterte Berlioz 1863 wiederum auf Reisen das Ritterkreuz der Hohenzollern auf der Bühne angeheftet bekam, just nachdem er die ersten beiden Sätze der HaroldSymphonie dirigiert hatte, war er derart „von Freude erfüllt", dass alles Folgende zu einer persönlichen Angelegenheit wurde. „Ich spielte mir wirklich die Orgie aus Harold für mich selbst, ohne an das Publikum zu denken, auf meine Weise, wie rasend; ich knirschte dabei mit den Zähnen. “75 Berlioz schildert die Verwirklichung einer in der Musik angelegten Verschmelzung seiner selbst mit den feiernden Briganten. Das Dirigieren verwandelte sich für ihn von einer öffentlichen Konzertdarbietung in eine private Theatererfahrung des latenten Symphonieinhalts. Die Ehrung rief neben der freudigen Genugtuung eine Wut über die ihm in seinem Heimatland verwehrt gebliebene Wertschätzung wach. Mit der hehren Beute an der Brust schüttelte er einmal die Verbitterung von sich, mit der er sonst auf sein Leben zurücksah, um darin nur die Karikatur jenes Nationalkünstlers zu erblicken, der er hatte sein wollen, während er sein Brot im Ausland vagabundierend ergaunern musste.

\section{Versöhnungswerk}

Die Orgie und die obskuren Inhalte des Programms umgaben das Finale mit dem Schwefelgeruch des Unsittlichen. Berlioz widerstand der Versuchung, weitere Aufklärung zu schaffen und Inhalte zu bestimmen, die die Aufmerksamkeit von den symphonischen Qualitäten fortgelenkt hätten. Diese nämlich weisen in eine andere, klassisch gegründete Richtung. Nichts entsprach Byrons Art besser als solche Zweischneidigkeit; die HaroldDichtung selbst gipfelt in einer gewaltigen Spannung zwischen Infamie und Versöhnung: Der letzte ,italienische“ Canto verbannt die lebendigen Rachegelüste aus der Diesseitigkeit der Pilgerfahrt. Die Klage wird in den Strophen cxxx ff. einem numinosen Anwalt übertragen: „Time, the avenger! (...) And thou (...) great Nemesis! (...) - Awake (...) Thou shalt take / The vengeance (...) a far hour shall (...) pile on human heads the mountain of my curse! / That curse shall be Forgiveness."

Neben der ambitionierten Fortentwicklung des klassisch-symphonischen Genres unternahm Berlioz sichtbar freundliche Schritte, den Anforderungen des Musikbetriebs entgegenzukommen. Ein erstes, demonstrativ an den Beginn der Harold-Symphonie gestelltes Angebot scheint die eröffnende Fuge. Während er in seinen frühen Musikfeuilletons ihre unzeitgemäße Ritualisierung wiederholt verhöhnte, ${ }^{76}$ rückte er sie hier in ernsthafter Bemühung wieder ins Bewusstsein. Die düstere Instrumentation macht es offensichtlich, dass die altehrwürdige Form sich rechtfertigen muss, indem sie sich neuen Qualitäten öffnet, ohne ihre schulmäßige Eigenart aufzugeben. Die Harold-Fuge wahrt in der Schmucklosigkeit ihrer Windungen ihren Stolz und wird zur düsteren Allegorie auf die Szene: Sie versinnbildlicht die traurigen Ruinen westlicher Zivilisation, die ja den Anstoß zu Harolds Pilgerreise geben. Entgegen der kritischen Position, die die Fuge zu einer „absurden“77 Praxis für die Unterrichts- und Prüfungszwecke des Conservatoire heruntergekommen sah, wurde hier eine Anstrengung unternommen, ihren Platz im modernen Musikleben zu rechtfertigen. In der Absicht folgte Berlioz seinem experimentierfreudigen Lehrer Anton Reicha, in der Ausführung mehr den revolutionären Ideen seines anderen Lehrers Jean-

75 Berlioz, Mémoires, Postface (1864).

76 Die einschlägigen Artikel sind vom 12. Juni 1833 in L'Europe littéraire sowie vom 27. Januar und 11. August 1834 in Le Renovateur; siehe CM 1, S. $100 \mathrm{ff} ., 146$ und 359.

77 Berlioz in L'Europe littéraire vom 12. Juni 1833, ebd., S. 100. 
François Lesueur. Die Fuge löste dessen Forderung einer beständigen Tonmalerei ein und bewies, dass diese mit den höchsten artistischen Ansprüchen zusammenstimmen konnte. Berlioz bezeugte, dass er die Sorge des Conservatoire um das Fortbestehen der Werte französischer Musik teilte. Verwehrt hatte er sich nur dagegen, sie als ein geschlossenes System hinzunehmen.

Ein anderes Zugeständnis lag in der Einwilligung, das Orchester mit einem Soloinstrument zu paaren, was sonst Sache der Instrumentalisten von Profession war. Was später zur „Symphonie en quatre parties avec alto principal“ geriet, wollte Berlioz zunächst wirklich im Sinne Paganinis ausführen. Dieser hatte sich ein spektakuläres Konzert vorgestellt, dass es ihm erlaubt haben würde, „immerzu zu spielen“,78 ganz wie in der Sonata per la Grand' Viola e Orchestra, die er 1834 zur Vervollständigung seines Reiserepertoires ohne jedwedes Tacet gestaltete. Bereitwillig hatte sich Berlioz an solch virtuosen Passagen versucht: An einer überklebten Stelle im Manuskript kann man es erkennen. ${ }^{79}$ Dann aber schloss er mit seinem Beobachterkonzept das Problem des Heroischen, das sich mit jedem Solokonzert stellt, aus. Er entsprach damit der Vorgabe Byrons, dessen Harold ein isoliertes und von der Gesellschaft zurückgezogenes Leben führt. Kein Ehrgeiz stachelt ihn zu großen Taten; dem meritokratischen Ideal der Napoleonzeit widersteht er. Es stellte sich heraus, dass Paganinis Virtuosität mit solchem Phlegma konzeptuell unvereinbar war. Dass Berlioz diese Perspektive zumindest erprobt hatte, spricht gegen die Deutung der Symphonie als antiheroisch, zu der Mark Evan Bonds mit Blick auf die zu Beethovens Vorbild kontrastierende Finallösung gelangt. ${ }^{80}$ Ein solcher Umkehrschluss übersieht, dass auch die kontemplative Romantik, wo sie sich ihren Nachtgedanken und der Tugend des Vagen stellt, ihre heroischen Momente kennt. Die Verwegenheit des Finalsatzes, die Harolds Wesen an eine kritische Grenze führt, steht dafür beispielhaft ein.

In der Reihe der Bezeugungen einer biederen Gesinnung steht auch der ausgedehnte Gesang des Bratschenthemas im ersten Satz (Takte 36 bis 94). Die Conservatoire-Professoren belächelten ihren Kollegen Boieldieu und verachteten Rossini für deren Hang zur Melodik als funktionslosem Selbstwert. Man darf feststellen, dass auch Berlioz diese Qualität gemieden hatte und erst mit dem Haroldthema seine ideologische Verblendung ablegte. Ausgedehnte Melodien ohne Worte fehlen in Berlioz' Frühwerk. Die einzig vergleichbare Passage, in der es einer instrumentalen Melodie gestattet wird, sich um ihrer selbst willen zu entfalten, ist das Gratias der Messe von 1824. Doch in ihrer letztlichen Anwendung im langsamen Satz der Symphonie fantastique (ab Takt 20) wurde sie wiederum als dramatischer Charakter inmitten einer ländlichen Scène aux champs motiviert. Auch die langsame Einleitung zur Waverley-Ouvertüre kann nicht geltend gemacht werden, denn sie scheint eine spätere Zutat zu sein. Als François-Joseph Fétis die Ouvertüre 1829 hörte, vermochte er ihr nicht „die leiseste Spur einer Melodie“ abzulauschen. ${ }^{81}$ Da Partitur und Stimmen erst 1839 zum Druck gelangten, gibt es bislang keinen philologisch fundierten Beleg dafür, dass das überlieferte Autograph mit der Einleitung auf die Zeit der Uraufführung im Jahr 1828 zurückgeht.

Schließlich erscheint die Harold-Symphonie versöhnlich, indem sie sich zum Maßstab der symphonischen Tradition im Zeichen Beethovens bekennt. Schon oberflächlich zeugen

78 Berlioz, Mémoires, XLV/15.

79 NBE Bd. 17, Appendix I (a), S. $219 f$.

80 Mark E. Bonds, Sinfonia anti-eroica / Berlioz's Harold in Italy, in: ders., After Beethoven. The Imperative of Originality in the Symphony, Cambridge / Massachusetts 1996, S. 28-72, hier S. 32.

81 Revue Musicale, Bd. VI (November 1829), S. 349. 
davon ihre viersätzige Anlage und die an die Neunte gemahnenden Rekapitulationen zu Beginn des Finales. Allenthalben waltet die Sorge um eine nicht länger durch querstehende Tableaus unterbrochene Entfaltung. Harold in Italie antwortet so auf eine Selbstkritik an der Symphonie fantastique, wo sich die Idée fixe anderen Themen hemmend in den Weg gestellt hatte: Sie „schiebt sich beharrlich wie eine leidenschaftliche und vorübergehende Idee zwischen die ihr äußerlichen Szenen und lenkt von ihnen ab, während sich die Harold-Melodie über die Orchestermelodien legt, zu denen sie kontrastiert (...), ohne deren Entwicklung zu unterbrechen. “82 Damit wird einer einheitlichen formalen Entwicklung eigenen Rechts der Vorrang eingeräumt. Weil Berlioz dennoch einer genreübergreifenden Konzeption von dramatischer Musik verpflichtet blieb, konnte er auch im Falle von Harold en Italie auf die subjektive Perspektive der Idée fixe nicht verzichten. Er bewahrte sie, aber erlaubte ihr nicht länger, die Werkautonomie in Frage zu stellen.

Der Wunsch, dramatische und symphonische Vorstellungen besser zu synchronisieren, war zweifellos auch durch den Fehlschlag der Intrata di Rob-Roy McGregor im Jahr 1833 aufgekommen. Der erste Satz der Symphonie löst das Problem der in unseren obigen Betrachtungen zur Mary-Stuart-Musik als Intermezzi bezeichneten Themen. Berlioz hatte die dramatische Person der Intrata - auf deren Identität wir gleich zu sprechen kommen durch eine festgelegte instrumentale Farbe gekennzeichnet. Er folgte dabei einem Ansatz, den er erstmals in der Ouverture de La Tempête von 1829 erprobt hatte, wo sich der Geisterchor exklusiv mit dem Klavierklang paart. Da diese Musik 1832 zum Finale der Retour à la vie berufen wurde, war diese Idee einer fixen Instrumentation für Berlioz offenbar aktuell geblieben und konnte das dramatische Instrument der Idée fixe ersetzen. Als Solo für das Englischhorn mit Harfenbegleitung hoben sich die besagten Intermezzi der Intrata deutlich von ihrer symphonischen Kulisse ab, sie erfüllten auch wohl ihre dramatische Funktion, doch mit den sonst herrschenden symphonischen Variationen über das schottische Lied interagierten sie schlecht. Das zentrale Intermezzo, das fast ohne weitere Veränderungen zum Thema des Protagonisten der Harold-Symphonie bestimmt wurde (T. 36-94 im ersten Satz) ragt in der Intrata als plötzliches Larghetto aus dem Haupttempo, allegro non troppo, heraus, so dass der Eindruck eines plötzlichen Eintreffens des sein Instrument spielenden Künstlers entsteht; dazu mischen sich die ihm gespendeten Beifallsbekundungen: Die ersten vier Takte werden von einem Tutti im Haupttempo unterbrochen (T. 264-275), bevor die Larghetto-Ballade wieder aufgenommen und zum Abschluss gebracht werden kann, wonach sie vom ganzen Ensemble wiederholt wird (T. 301-327).

Vergeblich sucht man eine vergleichbare Szene in Walter Scotts Roman Rob Roy; der Titel scheint nur ein imaginäres Ambiente für das schottische Lied zu stellen. Das zentrale Intermezzo könnte weit wahrscheinlicher ein Relikt aus einem frühen Opernprojekt nach Walter Scotts The Talisman sein, das Berlioz 1827 aufgegeben hatte. Zu einer zentralen Nummer dieser Oper mit dem Titel Richard en Palestine war eine „allegorische Ballade“ des Trouvère Blondel de Nesle bestimmt. Auch wenn der Sänger hier gemäß der Romanvorlage nur eine Nebenfigur war - anders als jener Blondel aus Grétrys Erfolgsoper Richard Cour de Lion von 1784, die zur Restaurationszeit wieder zu Ehren gelangt war - hatte Berlioz doch große Hoffnungen in diesen Charakter und seine Szene gesetzt: „Hüten Sie sich“, hatte er seinen Librettisten gewarnt, „mir irgendetwas Leichtes für Blondel anzubieten; das ist ein Hauptstück, verleihen sie ihm eine Art ossianische Inspiration in einem träumerischen

82 Berlioz, Mémoires, XLV/16. 
und ungezähmten Stil“ 83 Sieht man auf die Beharrlichkeit, mit der Berlioz Blondels Verse im Auge behielt, ${ }^{84}$ darf man annehmen, dass sich auch musikalische Vorstellungen schon gebildet hatten. Mit dem Bardengenre verband sich der Anspruch zur Nation zu sprechen, eine Berufsperspektive, die Berlioz damals wie auch 1834 noch - denkt man an die Überarbeitung der Heroischen Szene - verfolgte. Er eiferte mit dieser Hommage seinem hochverehrten Lehrer Lesueur nach, dessen Rang als Staatskomponist sich nicht zuletzt der Oper Ossian ou les Bardes verdankte.

In der Symphonie ist die grandiose Wiederholung der Solomelodie ab Takt 73 gegenüber der Vorgabe der Intrata ab Takt 301 beträchtlich überarbeitet (Notenbeispiel 9). Sie folgt ihr zwar thematisch getreu und weist dieselben beiden Perioden (I und II) mit Vorderund Nachsatz auf, wobei der zweite Nachsatz ein zweites Mal erklingt (II/3); doch während das Soloinstrument und sein Begleiter, die Harfe, im Modell in einem gemeinsamen Tutti mit dem Orchester verschmelzen, erscheinen sie jetzt metrisch verschoben und außer Phase wie ein enger Kanon oder ein widerhallendes Echo. Auch in der Symphonie wurden Soloinstrument und Harfenakkompagnement in den Takten 38 bis 70 als Einheit eingeführt; an dieser Stelle nun sind sie gegeneinander in Szene gesetzt und dabei durch charakteristische Farben gestärkt. Erst zuletzt (II/3) werden sie wieder zusammengeführt. Die Bedeutung dieser Verschiebung des Soloparts sowie ihrer Umkehrung bei II/3 liegt nicht auf der Hand.

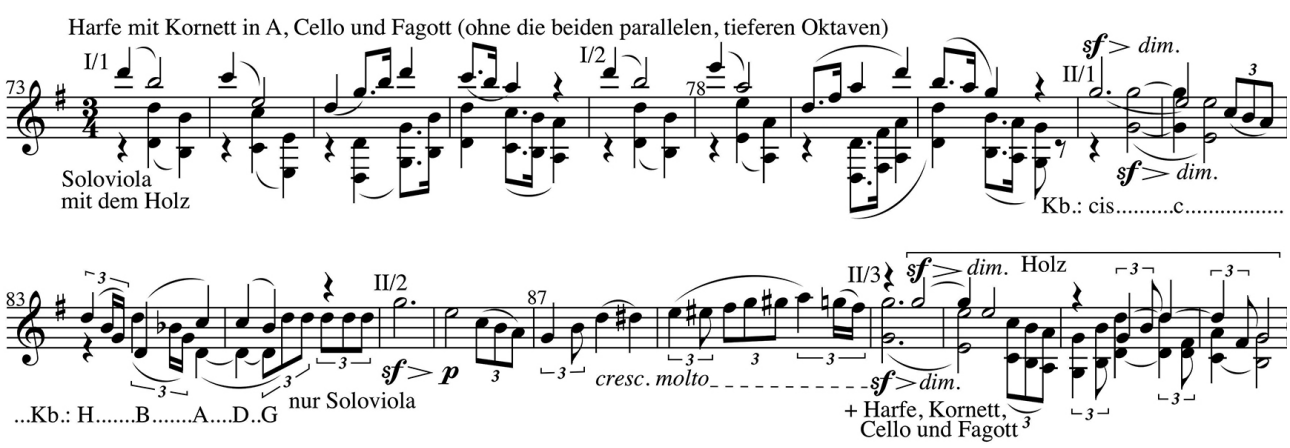

Notenbeispiel 9: Erster Satz, Wiederholung des gesanglichen Themas (ohne Figurationen)

Anders als im Bardenintermezzo der Intrata wird keine Handlung suggeriert. Harold besticht nicht durch Taten, sein treffend beobachtender Charakter ist es, der die Symphonie in allen Teilen motiviert. Erst durch den Reichtum seines Wesens erlangt das einfache gesangliche Thema mit seiner banalen Diatonik Interesse. Der aufwendig gestaltete Gipfelpunkt seines Porträts ist eine Verheißung und weist Harold an dieser Stelle erst vorläufig als Berufenen aus. Die Gestaltung rührt in dreierlei Hinsicht an die Frage der Klassizität: Mit dem Imitationsprinzip wirft sie ein ästhetisches Kardinalproblem auf, darüber hinaus setzt sie das Kapriziöse gebunden in Szene und bekräftigt zuletzt den Anspruch, dass Traditionen eher geführt als befolgt werden müssen.

1. Das klassischerweise alle Künste einende Imitationsprinzip wurde von Lesueur und dessen Schülerkreis unter dem Schlagwort der „Malerei“ als Dogma treu bewahrt. Berlioz fasste den Vorgang der Naturnachahmung in einer Erweiterung seiner Rompreiskantate

83 An Léon Compaignon am 29. Juni 1826, CG 1, S. 123.

84 Vgl. auch den Brief an Léon Compaignon vom 25. Juli 1826, ebd., S. 131. 
von 1827 in folgendes Bild: Ein Hirte, verkörpert durch eine ferne Soloklarinette, horcht dem Lispeln der Harfe des von Bacchantinnen erschlagenen Orpheus nach. Mit ihrer Hilfe versucht er eine Melodie, die er einst vom Sänger vernahm, die aber der Erinnerung nicht mehr ganz präsent ist, wieder zusammenzubringen. Im Glauben, er spüre klassischen Werten nach und erinnere sich ihrer, kommt er ihr doch nur, indem er sich einem Naturphänomen öffnet, auf die Spur. Zwar lauscht er den Harmonien der magischen Harfe nach - im Notenbeispiel 10 die ersten beiden Fermaten -, doch die Erinnerungslücke, die sich ihm im Takt 19 mit der dritten Fermate entgegenstellt, schließt er ohne deren starke Zeichen allein unter dem Klang eines Streichertremolos, also dem schwachen Geräusch des Windes. Der künstlerische Erfolg ist nicht ausschließlich der Triumph einer seit Ewigkeiten währenden Tradition, die im Bild der Lyra Gestalt annimmt, er verdankt sich der Fähigkeit des Sängers, sich auf den Naturstoff einzulassen, auch wenn er nur unbestimmte Vorformen bietet.

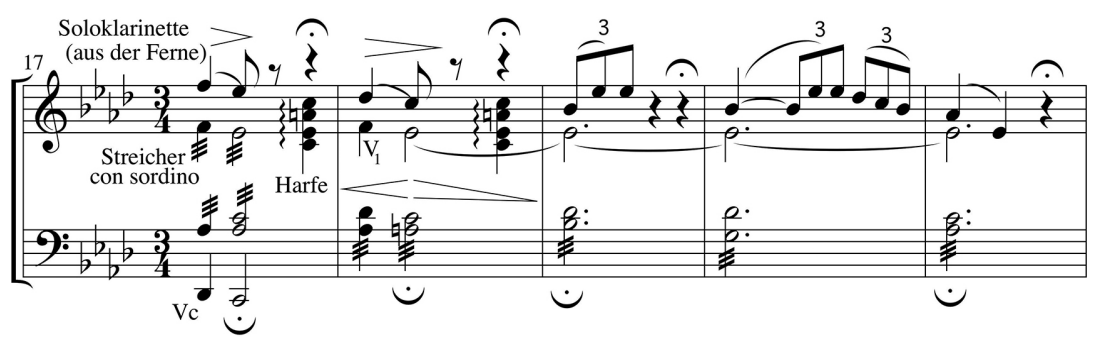

Notenbeispiel 10: Schlusstableau aus Berlioz' Rompreiskantate Orphée (1827)

Der Umgang des auf sich gestellten Künstlers mit solchen Vorformen wird in der HaroldSymphonie vielerorts thematisiert. Nicht allein nimmt der Solist die rustikalen Melodietypen des zweiten und dritten Satzes zum Anlass eigener Reflektion. Auch Ungeformtes beschäftigt ihn, besonders im ersten Satz. Vor der zerpflückten Gestalt, welche die Motive des Hauptthemas vor seinem Geiste annehmen, hält er zunächst inne und verstummt (T. 93f.), um ihnen nachzulauschen (T. 95-125). Erst nach einigem Tasten (T. 125-130) gelingt es ihm dann, es selbst gediegen zustande zu bringen (T. 131ff).

Solcherlei progressive Formung ereignet sich in der Reprise des gesanglichen Themas (Notenbeispiel 9) nicht mehr. Allerdings hatte auch dessen klare Gestalt erst aus der düsteren Ruinenlandschaft der Fugenintroduktion heraus geborgen werden müssen; in der dortigen Orchesterexposition (T. 14-29) erschien es noch vage und in Moll. In der Soloexposition erst (T. 36-71) ersteht es in voller Gestalt und kann gar variiert werden. An der Reprise interessiert im Gegenteil, unter welchen Umständen und in welcher Weise das Modell verlassen und die getreue Imitation überhöht werden kann.

2. Inmitten der Reprise nimmt vor dem Beschluss des Themas (siehe Notenbeispiel 11) das launige Ausscheren der Viola (T. 87f.) die Position der Solokadenz ein. Berlioz reduziert das Caprice des Solos auf periodengerechte vier Takte, statt einen unbegrenzten Raum freier Intuitionen ex tempore freizugeben, aus dem ein Solist vom Schlage Paganinis etwas zu machen verstanden hätte. Die Viola steht, statt ihre Einzigartigkeit solistisch abgehoben zu behaupten, mit dem kaum weniger einfallsreichen Orchester in Verbindung. Die von der puren Diatonik des Themas abstechende lineare Chromatik der Solostimme geht zuerst von den Streichern aus (T. 85f.) und findet in den Begleitharmonien der Holzbläser (T. 87-89) einen Widerhall. Allerdings setzt die Viola mit ihrem Erwachen aus der Gefolgschaft zu 
einem nur provisorischen Nachsatz an, der von einem harmonischen Nebengleis (Es-Dur statt G) abgeht. Der Abschnitt präsentiert bei Takt 87 eine konsolidierende Variante zur pathetischen Geste des Vordersatzes, der an paralleler Stelle (T. 83) in einer Irritation des Tongeschlechts endete. Die Basschromatik cis-c-h-b ab T. 81 (siehe Bsp. 9), über deren schicksalhafte Bedeutung im Finalsatz schon zu sprechen war, hatte sie provoziert. Der Nachsatz wirkt so betrachtet wie eine Richtigstellung. Harold wächst über seine Rolle als naiver Romanzensänger (T. 36-49) und Träumer (T. 50-70) hinaus und drängt darauf, sich in einem öffentlichen Kontext geltend zu machen als vollständiger Künstler.

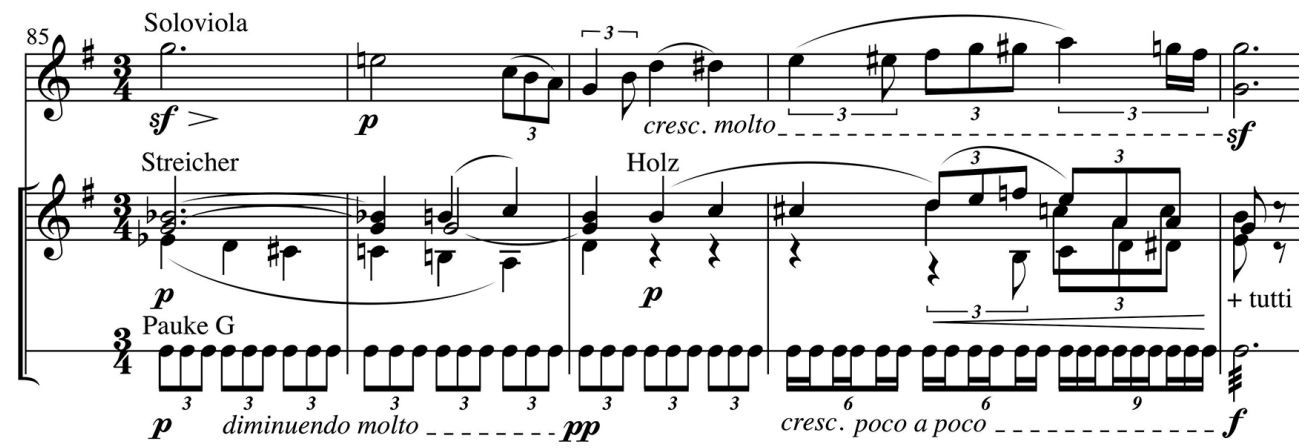

Notenbeispiel 11: Provisorischer Nachsatz des gesanglichen Themas (II/2), erster Satz T. 85-89

3. Die Verbindung des Sängers mit der Harfe, die ja auch in der Äolsharfenmusik und in den Intermezzi der Intrata exponiert wird, ist dafür maßgeblich. Das Saiteninstrument verkörpert im Mythos des Orpheus das elementare und lehrbare Tonsystem. Es steht für das Klassische und Kunstgerechte, das dem Gesang ein kontrolliertes Wirkungsfeld bereitet. Erst durch die Paarung des Solos mit der Harfe wird jenes Bild des Barden vollständig, welches das wesentliche Element von Berlioz' Selbstporträt als Harold en Italie darstellt, denn in allen drei Stadien, die sich in seiner eigenhändigen Partitur nachweisen lassen, ${ }^{85}$ ist es auf die eine oder andere Weise verwirklicht.

Verbunden sind Viola und Harfe in der mit Blick auf Paganinis Künstlertum erstellten, überklebten ersten Fassung der Passage, wo sie sich als motorische Einheit gegen den Cantus firmus des Orchesters unter der Führung des Kornetts behaupten (siehe Anm. 79). In der ersten auf der Überklebung sichtbaren neuen Version gingen Harfe und Viola sogar zunächst unisono, bevor Berlioz auf die Idee kam, die Einheit aufzutrennen und beide gegeneinander zu verschieben. Er wählte nun statt des Kornetts in $D$, das in der Lage von Fagott und Cello spielte, eines in $A$, das eine Oktave höher klingt, zur besseren Unterstützung der vorangehenden Stimme mit der Harfe. Auch das Solo blieb nicht auf sich gestellt und fand Rückhalt in den zusätzlich ins Spiel gebrachten Holzbläsern. Ebenfalls versetzt steht eine schwach sichtbare Solocellostimme am oberen Rand. Die in mehreren aufeinander folgenden Schritten in die fertige Partitur hineingetragene Krise des Unisono löst dessen Einheit in eine Dialektik des Folgens und Führens auf. Die Vorstellung einer Führung durch die Autorität der Künste prägte im postrevolutionären Frankreich das populäre romantische Bild des Barden, für das man Louis-Antoine-François de Marchangys La Gaule poétique von 1813 als Zeugen aufrufen kann. In der Ausübung seiner Kunst wird der Sänger sehend und übt einen über jegliche Anmaßung erhabenen und legitimen gesellschaftlichen

85 Siehe dazu die autographe Partitur, S. 16ff., auch als Internetressource auf gallika.bnf.fr. 
Einfluss aus. Zur Führung gelangt die Viola erst (II/3) unter der Bedingung einerseits einer treuen Gefolgschaft (Periode I und II/1) des im Harfenklang konnotierten Klassischen und zum anderen durch die Überwindung eines selbstbezogenen, reflexiven Stadiums provisorischer Vorschläge (II/2), das von der Klassik absieht. Die melodische Chromatik, welche in den Takten 54 bis 61 noch vagabundierte, strebt ab Takt 87 einem nunmehr klaren Ziel zu und drängt auf die ultimative Wiederherstellung der Einheit mit der Harfe. Harold gelangt zu einem reifen Standpunkt jenseits von Klassizismus und Romantizismus.

Auch die weiteren Tableaus der Symphonie, die sich in instrumentatorischen Gegenüberstellungen verwirklichen, können als Zeugnisse einer sensiblen Poetik angesehen werden. Sie boten eine Alternative zur deskriptiven Dramatik der Symphonie fantastique. Kraft ihrer meinte Berlioz, das Programm der Harold-Symphonie unentwickelt lassen zu dürfen, den Deutungsbedarf an das Publikum weitergebend mit den Worten: „Ich bitte Sie ernsthaft, mich darüber aufzuklären, was eine Symphonie namens Harold überhaupt bedeuten soll.“ 